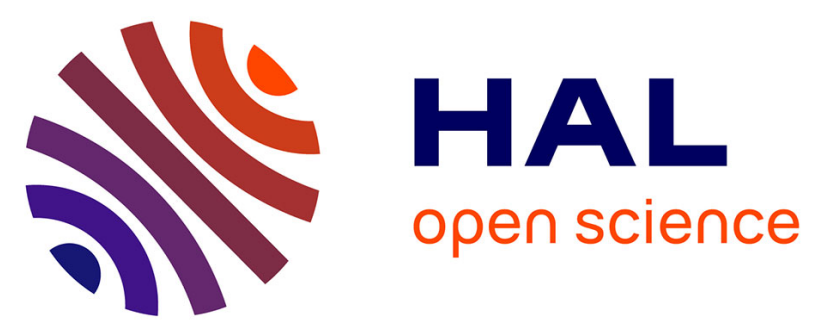

\title{
A new type of triboelectric nanogenerator with self-actuated series-to-parallel electrical interface based on self-synchronized mechanical switches for exponential charge accumulation in a capacitor
}

Mohamed Aymen Ben Ouanes, Hatem Samaali, Dimitri Galayko, Philippe Basset, Fehmi Najar

\section{To cite this version:}

Mohamed Aymen Ben Ouanes, Hatem Samaali, Dimitri Galayko, Philippe Basset, Fehmi Najar. A new type of triboelectric nanogenerator with self-actuated series-to-parallel electrical interface based on self-synchronized mechanical switches for exponential charge accumulation in a capacitor. Nano Energy, 2019, 62, pp.465-474. 10.1016/j.nanoen.2019.05.049 . hal-02295416

\author{
HAL Id: hal-02295416 \\ https://hal.science/hal-02295416
}

Submitted on 25 Oct 2021

HAL is a multi-disciplinary open access archive for the deposit and dissemination of scientific research documents, whether they are published or not. The documents may come from teaching and research institutions in France or abroad, or from public or private research centers.
L'archive ouverte pluridisciplinaire HAL, est destinée au dépôt et à la diffusion de documents scientifiques de niveau recherche, publiés ou non, émanant des établissements d'enseignement et de recherche français ou étrangers, des laboratoires publics ou privés.

\section{(ㅇ)(1) $\$$}

Distributed under a Creative Commons Attribution - NonCommerciall 4.0 International 


\title{
A new type of triboelectric nanogenerator \\ with self-actuated series-to-parallel electrical interface
}

based on self-synchronized mechanical switches for exponential charge accumulation in a capacitor

\author{
M. A. Ben Ouanes ${ }^{1,2}$, H. Samaali ${ }^{1,2,3}$, D. Galayko ${ }^{4}$, P. Basset ${ }^{2 *}$ and F. Najar ${ }^{1^{*}}$ \\ ${ }^{1}$ Applied Mechanics and Systems Research Laboratory (LR03ES06), Tunisia Polytechnic \\ School, BP 743, La Marsa 2078, University of Carthage, Tunisia. \\ ${ }^{2}$ Université Paris-Est, ESYCOM, ESIEE Paris-UPEM-CNRS-CNAM, \\ Noisy-le-Grand 93162, France \\ ${ }^{3}$ Sousse National Engineering School, BP 264 Sousse Erriadh 4023, \\ University of Sousse, Tunisia. \\ ${ }^{4}$ Sorbonne Université, CNRS, UMR 7606, LIP6, 75005 Paris, France
}

Corresponding authors: philippe.basset@esiee.fr, fehmi.najar@ept.rnu.tn

\begin{abstract}
We present a new concept for impact-based triboelectric nanogenerators (TENG) inspired from the electrostatic machines of the $18^{\text {th }}$ century. With this system, the electrical energy converted from the mechanical domain is automatically accumulated in a large capacitance without the need of diodes. Our TENG has three electrodes and self-synchronized / selfactuated mechanical switches, which automatically and repeatedly connect the capacitances of the system according to their series and parallel configurations in order to reproduce a behavior similar to the Bennet's charge doubler. The movable and freestanding electrode is covered with triboelectric patches that drastically decreases the start-up time. The output voltage, and so the harvested energy, increases exponentially until either the output voltage reaches the air dielectric breakdown or a saturation occurs because the electrostatic forces
\end{abstract}


become comparable to the mechanical ones. We have developed a complete numerical model that takes into account both electrical and mechanical forces and is able to show the saturation phenomena due to the high electromechanical coupling occurring at high voltage. This model has been validated with practical experiments where the prototype were excited with a sinusoidal acceleration of $0.2 \mathrm{grms}_{\mathrm{r}}$ at $5 \mathrm{~Hz}$. This new and diode-free concept can be applied to any TENG having at least one variable capacitor to boost the mechanical-toelectrical energy conversion.

Keywords: Vibration energy harvester, Electrostatic transduction, Bennet's charge doubler, Triboelectric effect, Mechanical switches

\section{Introduction}

Wireless sensors and internet of things (IOT) based systems can be considerably improved thanks to energy harvesting devices. Extracting energy from vibrations surrounding lowpower devices is a good alternative to battery, especially when a large deployment of these devices is envisaged. Such kinetic or vibration energy harvesters (K/VEH) usually include a mobile mass to capture the kinetic energy from the vibrations and a transducer that transforms them into useful electrical energy. Several transducer mechanisms can be used, like electromagnetic, piezoelectric or electrostatic ones.

With electrostatic transducers, one or several variable capacitors are required to convert the kinetic energy into electricity. The level of converted energy is strongly related to the capacitance ratio $C_{\operatorname{Max}} / C_{\min }$ of the electromechanical transducer. Various designs have been proposed in the literature, most of them using MEMS technologies, and having inplane linear variation of the capacitance [1][2] or gap-closing devices [3][4]. A more sophisticated optimized in-plane triangular electrodes for reducing the air damping was also introduced by Lu et $a$ l in [5].

Classical conditioning circuits for electrostatic KEH (e-KEH) are based on charge-pump circuits where diodes and/or mechanical switches are used. It typically works with a two stages cycle [6]. First, a variable capacitor is charged when at its maximal value. Then the capacitor is decreased through the application of external inertial forces on one movable electrode, while the electrostatic force tried to prevent its displacement. This converts mechanical energy into electricity, which can be stored in another capacitor denoted 
reservoir capacitance $C_{\text {res }}$. The process is repeated until an optimum voltage is reached across $C_{\text {res. }}$. At this point, a secondary circuit is used to (partially) discharge $C_{\text {res }}$ before its saturation, and the energy harvesting cycle can restart. The control of the different steps can be achieved by implementing transistor-based switches [7][8][9] or diodes [12][11][12]. A similar approach is used with triboelectric nanogenarators [13]. Chiu also proposed the use of mechanical switches to replace diodes or the electronic control of transistors [14], followed by Samaali et al [15].

All previously cited rectifier circuits, whatever they are made of diodes or switches, can be denoted as stable charge-pump [16][16], sometimes followed with a Buck-type inductive feedback for de-saturating the reservoir capacitance. Unstable charge-pump can also be used. They are typically based on the Bennet's influence machine [18][19]. They allow an exponential increase with time of the harvested vibrational energy thanks to one or two parallel-plate variable capacitors with synchronized electrical connection between the electrodes. Dorzhiev et al implemented such Bennet's doubler KEH at the microscale using a single gap-closing MEMS variable capacitor with interdigitated electrodes [20]. Lefeuvre et al proposed a circuit to overcome the limitation related to the variable capacitance max-to-min ratio inherent to the Bennet charge doubler [21], and Karami et al proposed a generalization of such kind of circuits that have in commun a rectangular QV cycle [22]. To avoid the drawbacks of diodes like reverse current, positive and Zener reverse voltage threeshold, Ouanes et al at macroscale [23], and Le et al at microscale [24], separately and concurrently proposed the use of mechanical into a vibrational KEH based on the Bennet charge doubler principle.

Triboelectricity has been introduced for kinetic energy harvesting using electrostatic transduction by Prof Zhong Lin Wang who first proposed the concept of TriboElectric Nano Generator (TENG) [25]. In [26], he proposed a comparison between TENGs and piezoelectric or electromagnetic generators based on Maxwell's equations. Numerous applications are envisaged, including large energy recovery from the oceans [27]. One drawback of TENGs is its very high voltage generation. However, we can take advantage of the induced air breakdown phenomena to directly charge a capacitor [28].

In [29], Hinchet et al observed that most TENG are actually similar to electret-based e$\mathrm{KEH}$ and share the same lumped-element circuit once in steady-state. So, recently it has been proposed to apply the Bennet circuit to TENG devices [16][30], leading to a larger 
output power. In this work, we propose a new type of TENG with a freestanding movable electrode like in [31][32], except that electrical energy converted from the mechanical domain is automatically accumulated in a large capacitance without the need of diodes. The device is based on the Bennet charge doubler principle and made of two asymetric gapclosing variable capacitances with a 3-electrode sandwich structures, having a mobile electrode in the middle and 3 self-actuated mechanical switches. The two faces of the freestanding electrode are covered with a triboelectric layer that induces additional charges at each contact. The inertial mass is supposed to be free of any elastic link and the mechanical switches play also the role of stoppers. The manuscript is structured as follow: the next section describes the principle of the new TENG, section 3 presents its electromechanical model and section 4 compares the simulations with experimental results.

\section{Description of a tribo-enhanced Bennet doubler}

\section{Principle of operation}

A side-view schematic of the proposed TENG is illustrated in Fig. 1. It is composed of 3 electrodes: side electrodes $\mathrm{A}$ and $\mathrm{C}$ being fixed to the external frame and a central one $\mathrm{B}$ moving in-between. Inertial forces are induced by an externally applied acceleration. The position of electrode $\mathrm{B}$ results in two variable capacitances $C_{b a}$ and $C_{b c}$. The conditioning circuit is composed by three mechanical switches $S_{1}, S_{2}$ and $S_{3}$, all self-activated by the motion of B. In addition, a large reservoir capacitor $C_{\text {res }}$ is needed to collect the harvested energy.

The three switches interconnect the three electrodes during the displacement of the central electrode $\mathrm{B}$ in order to reproduce the behaviour of the electrostatic machine invented by Bennet in 1787 [18] when periodic vibrations are applied. $S_{1}$ and $S_{3}$ connect $B$ and $C$ to $C_{\text {res }}$ res electrode B. When electrode B is close to electrode A, the switches $S_{1}$ and $S_{2}$ are ON (Fig. 1b) and the three capacitors are in parallel. $C_{b a}$ is at its maximum value $C_{b a}^{M a x}$, whereas $C_{b c}$ is minimal at $C_{b c}^{\min }$. When the electrode $\mathrm{B}$ moves in-between $\mathrm{A}$ and $\mathrm{C}$, all switches are OFF (Fig. 1a). When B is close to $\mathrm{C}, S_{3}$ turns $\mathrm{ON}$ leading to the series configuration. Then $C_{b c}$ turns to its maximum value $C_{b c}^{M a x}$ and $C_{b a}$ turns to its minimum value $C_{b a}^{\min }$ (Fig. 1c).

In the following, we analyse the evolution of the charges in the capacitors. Let's start the process when the capacitance $C_{b a}$ is at its maximum value $C_{b a}^{M a x} . S_{1}$ and $S_{2}$ are ON and the capacitors $C_{b a}, C_{b c}, C_{\text {res }}$ are in parallel (Fig. 1b), so they have the same electrical potential $V^{P, I}$ : 


$$
V^{P, i}=V_{b a}^{P, i}=V_{b c}^{P, i}=V_{r e s}^{P, i}=Q_{b a} / C_{b a}^{M a x}=Q_{b c} / C_{b c}^{m i n}=Q_{r e s} / C_{r e s}
$$

where $P$ indicates the parallel configuration and $i$ the mechanical cycle number. $Q_{b a}, Q_{b c}$ and $Q_{r e s}$ are the charges associated to each capacitor $C_{b a}, C_{b c}$ and $C_{\text {res }}$ respectively.

When $B$ moves towards $C$, all switches are in open-circuit: $C_{b a}$ starts decreasing while $C_{b c}$ increases. The device is in a constant-charge mode and according to the charge conservation law, $V_{b a}$ increases, $V_{b c}$ decreases and $V_{\text {res }}$ remains equal to $V^{P, i}$. We can write the following equalities, just before the contact between $B$ and C:

$$
\left\{\begin{array}{c}
Q_{b c}^{S^{-}, i}=V^{P, i} C_{b c}^{\min }=V_{b c}^{S^{-}, i} C_{b c}^{M a x} \\
Q_{b a}^{S^{-}, i}=V^{P, i} C_{b a}^{M a x}=V_{b a}^{S^{-}, i} C_{b a}^{\min } \\
Q_{\text {res }}^{S^{-}, i}=V^{P, i} C_{\text {res }}=V_{\text {res }}^{S^{-}, i} C_{\text {res }} \Rightarrow V^{P, i}=V_{\text {res }}^{S^{-}, i}
\end{array}\right.
$$

where $S^{-}$indicates the moment just before $S_{3}$ is $\mathrm{ON}$, i.e. just before the series configuration of the capacitors. $C_{b a}^{\min }$ and $C_{b c}^{\operatorname{Max}}$ are the minimal and maximal value of $C_{b a}$ and $C_{b c}$ respectively.

At the moment $S^{+}$corresponding to the moment just after $S_{3}$ becomes ON, all capacitors are in series (Fig. 1c). We can assume that the potential across $C_{b c}, C_{b a}$ and $C_{r e s}$ are the same at $S^{-}[33]$. Consequently:

$$
\left\{\begin{array}{l}
V_{r e s}^{S^{-}, i}=V_{r e s}^{S^{+}, i} \\
V_{b c}^{S^{-}, i}=V_{b c}^{S^{+}, i} \\
V_{b a}^{S^{-}, i}=V_{b a}^{S^{+}, i}
\end{array}\right.
$$

In order that $C_{b a}$ starts to give its charges to the network capacitors $\left(C_{b c}, C_{r e s}\right)$, it is required that:

$$
\begin{aligned}
& V_{b a}^{S^{+}, i}>V_{b c}^{S^{+}, i}+V_{r e s}^{S^{+}, i} \\
& \leftrightarrow V^{P, i} \frac{C_{b a}^{M a x}}{C_{b a}^{\min }}>V^{P, i} \frac{C_{b c}^{\min }}{C_{b c}^{M a x}}+V^{P, i} \\
& \leftrightarrow \frac{C_{b a}^{\text {Max }}}{C_{b a}^{\min }}>\frac{C_{b c}^{\min }}{C_{b c}^{\text {Max }}}+1
\end{aligned}
$$

At the contact $S^{+}$, the total charge in the system is given by:

$$
Q_{t o t}^{S^{+}, i}=V_{b a}^{S^{+}, i} \cdot C_{b a}^{\min }+\left(V_{b c}^{S^{+}, i}+V_{r e s}^{S^{+}, i}\right) \cdot C_{e q}
$$

where $C_{e q}=\frac{C_{b c}^{M a x} \cdot C_{r e s}}{C_{b c}^{\text {Max }}+C_{r e s}}$. 


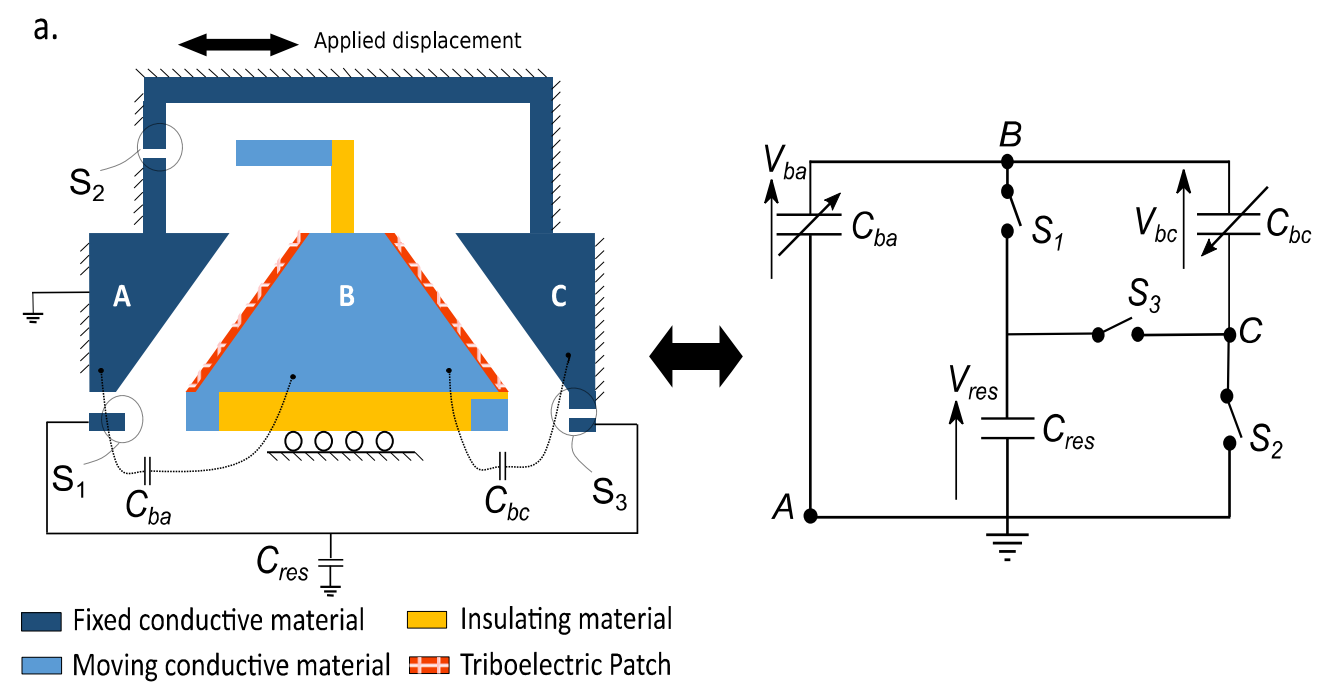

Moving conductive material Triboelectric Patch

b.
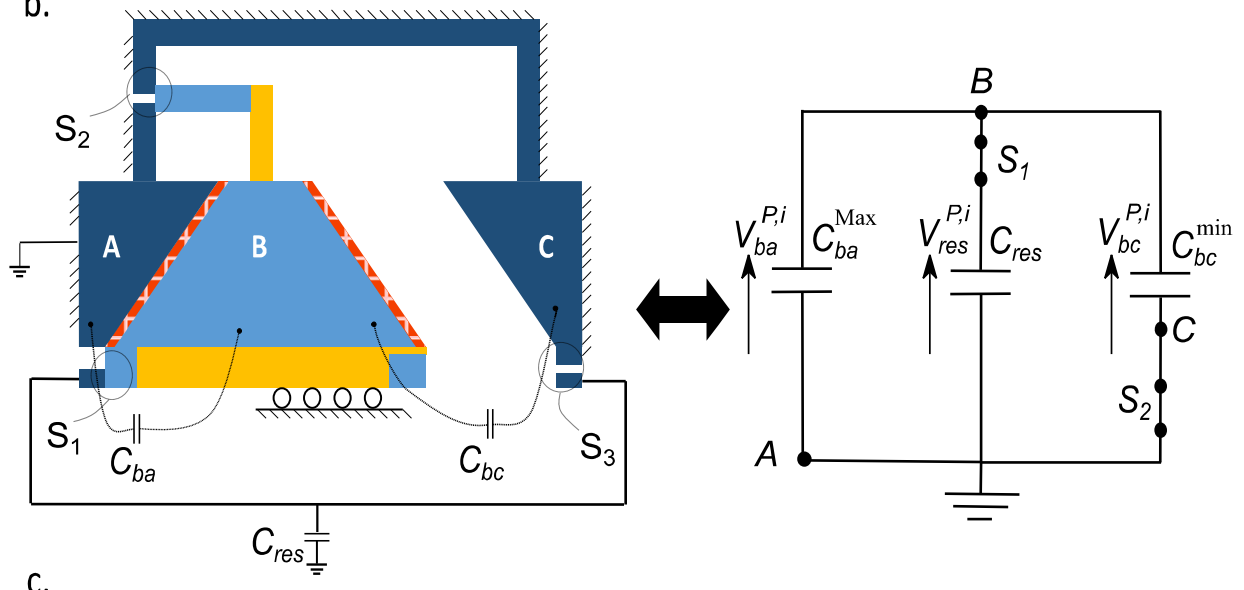

C.
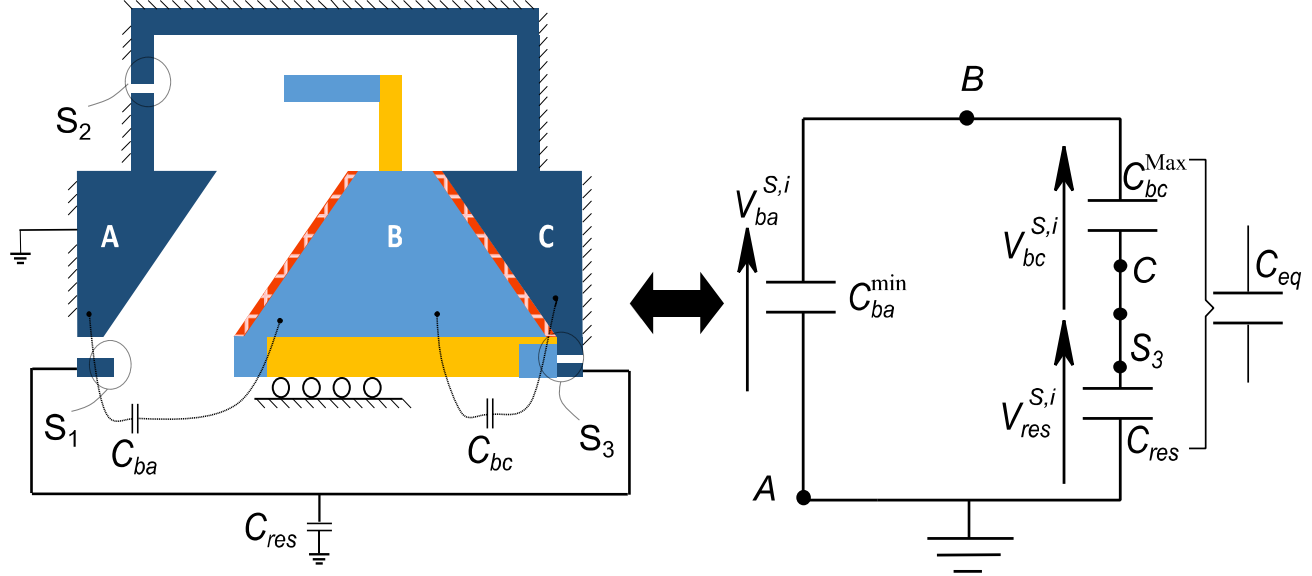

Fig. 1. Side-view schematics and equivalent electrical circuits of the F-TENG in its 3 configurations assuming no contact resistance. a. The sliding electrode B is isolated $\left(S_{1}, S_{2}\right.$ and $S_{3}$ are open). b. Electrode B is contacting electrode A ( $S_{1}$ and $S_{2}$ are closed, $S_{3}$ is open). c. Electrode B is contacting electrode C ( $S_{3}$ is closed, $S_{1}$ and $S_{2}$ are open). 
On the other hand, at the steady state of the series configuration denoted by $S$ the total charge is:

$$
Q_{t o t}^{S, i}=V_{b a}^{S, i} \cdot\left(C_{b a}^{m i n}+C_{e q}\right)
$$

According to the charge conservation law:

$$
Q_{\text {tot }}^{S^{+}, i}=Q_{t o t}^{S, i}
$$

Equalizing Eq.(5) and Eq.(6) then replacing with the equalities in Eq.(2) and Eq.(3), we get:

$$
V_{b a}^{S, i}=V^{P, i} \frac{\left(1+\frac{C_{b c}^{\min }}{C_{b c}^{M a x}}\right) C_{e q}+C_{b a}^{M a x}}{C_{b a}^{\text {min }}+C_{e q}}
$$

Now we can determine the charge $\Delta Q^{S, i}$ given from $C_{b a}^{\min }$ to $\left(C_{b c}, C_{r e s}\right)$ :

$$
\Delta Q^{S, i}=Q_{b a}^{P, i}-Q_{b a}^{S, i}=V^{P, i} C_{b a}^{M a x}-V_{b a}^{S, i} C_{b a}^{\min }
$$

Substituting Eq.(8) in Eq.(9), we get:

$$
\Delta Q^{S, i}=V^{P, i}\left[C_{b a}^{M a x}-\frac{\left(1+\frac{C_{b c}^{\text {min }}}{C_{b c}^{M a x}}\right) C_{e q}+C_{b a}^{M a x}}{\left(C_{b a}^{\text {min }}+C_{e q}\right)} C_{b a}^{\min }\right]
$$

At the end of the first phase $C_{b a}^{M a x} \rightarrow C_{b a}^{\min }$, the transducer $C_{b a}$ gives the charge $\Delta Q^{S, i}$ to $C_{e q}$ that is received by each capacitors $C_{b c}$ and $C_{r e s}$. As a result, the total variation of the charge in the system $\left(C_{b a}, C_{b c}, C_{r e s}\right)$ is:

$$
-\Delta Q^{S, i}+2 \Delta Q^{S, i}=\Delta Q^{S, i}
$$

Now $C_{b a}$ increases from $C_{b a}^{\min }$ to $C_{b a}^{M a x}$ while $C_{b c}$ decreases, all switches are open and the device is in constant charge mode. At $C_{b a}^{M a x}, S_{1}$ and $S_{2}$ becomes $\mathrm{ON}$ and the three capacitors are in parallel again. The total charge at the moment $\left(P^{-}, i\right)$ just before the contacts is the same as the previous series' state $(S, i)$ but also the same as the charge just after the ON contact $\left(P^{+}, i+1\right)$ and finally also the same at the steady state of the new parallel configuration $(P, i+1)$ :

$$
Q_{t o t}^{S, i}=Q_{t o t}^{P^{-}, i}=Q_{t o t}^{P^{+}, i+1}=Q_{t o t}^{P, i+1}
$$

Consequently, to define the total charge at the beginning of a new mechanical cycle $(i+1)$, we have to add the charge $\Delta Q^{S, i}$ to the capacitors in parallel:

$$
V^{P, i+1}\left(C_{b a}^{M a x}+C_{b c}^{m i n}+C_{r e s}\right)=V^{P, i}\left(C_{b a}^{M a x}+C_{b c}^{\min }+C_{r e s}\right)+\Delta Q^{S, i}
$$

Then at each cycle, the increase of the converted energy is given by: 


$$
E(i+1)=\frac{1}{2}\left(C_{b a}^{M a x}+C_{b c}^{m i n}+C_{r e s}\right)\left[V^{P, i+1^{2}}-V^{P, i^{2}}\right]
$$

Table 1: summarizes all the parameters of the system.

\begin{tabular}{|c|c|c|c|}
\hline Symbol & Signification & Symbol & Signification \\
\hline A & Electrode A & $P^{-}$ & Moment just before contact $S_{1}$ and $S_{2}$ are ON \\
\hline B & Electrode B & $P^{+}$ & Moment just after contact $S_{1}$ and $S_{2}$ are ON \\
\hline $\mathrm{C}$ & Electrode C & $V^{P, i}$ & $\begin{array}{l}\text { Electrical potential in the parallel } \\
\text { configuration associated to cycle } i\end{array}$ \\
\hline$S_{1}$ & Switch $S_{1}$ & $V_{b a}^{S, i}$ & $\begin{array}{l}\text { Electrical potential across } C_{b a} \text { in the series } \\
\text { configuration associated to cycle } i \text { at the steady } \\
\text { state }\end{array}$ \\
\hline$S_{2}$ & Switch $S_{2}$ & $V_{b a}^{S^{-}, i}$ & $\begin{array}{l}\text { Electrical potential across } C_{b a} \text { in the series } \\
\text { configuration associated to cycle } i \text { at moment } S^{-}\end{array}$ \\
\hline$S_{3}$ & Switch $S_{3}$ & $V_{b c}^{S^{-}, i}$ & $\begin{array}{l}\text { Electrical potential across } C_{b c} \text { in the series } \\
\text { configuration associated to cycle } i \text { at moment } S^{-}\end{array}$ \\
\hline$C_{b a}$ & $\begin{array}{l}\text { Capacitance between } \\
\text { electrode } B \text { and } A \text {. }\end{array}$ & $V_{\text {res }}^{S^{-}, i}$ & $\begin{array}{l}\text { Electrical potential across } C_{\text {res }} \text { in the series } \\
\text { configuration associated to cycle } i \text { at moment } S^{-}\end{array}$ \\
\hline$C_{b c}$ & $\begin{array}{l}\text { Capacitance between } \\
\text { electrode B and C. }\end{array}$ & $V_{b a}^{S^{+}, i}$ & $\begin{array}{l}\text { Electrical potential across } C_{b a} \text { in the series } \\
\text { configuration associated to cycle } i \text { at moment } S^{+}\end{array}$ \\
\hline$C_{\text {res }}$ & reservoir capacitance & $V_{b c}^{S^{+}, i}$ & $\begin{array}{l}\text { Electrical potential across } C_{b c} \text { in the series } \\
\text { configuration associated to cycle } i \text { at moment } S^{+}\end{array}$ \\
\hline$C_{b a}^{M a x}$ & $\begin{array}{l}\text { Maximal value of } \\
\text { capacitance } C_{b a}\end{array}$ & $V_{\text {res }}^{S^{+}, i}$ & $\begin{array}{l}\text { Electrical potential across } C_{\text {res }} \text { in the series } \\
\text { configuration associated to cycle } i \text { at moment } S^{+}\end{array}$ \\
\hline$C_{b a}^{\min }$ & $\begin{array}{l}\text { Minimal value of } \\
\text { capacitance } C_{b a}\end{array}$ & $Q_{b a}^{S^{-}, i}$ & $\begin{array}{l}\text { Electrical charges in } C_{b a} \text { in the series } \\
\text { configuration associated to cycle } i \text { at moment } S^{-}\end{array}$ \\
\hline$C_{b c}^{\operatorname{Max}}$ & $\begin{array}{l}\text { Maximal value of } \\
\text { capacitance } C_{b c}\end{array}$ & $Q_{b c}^{S^{-}, i}$ & $\begin{array}{l}\text { Electrical charges in } C_{b c} \text { in the series } \\
\text { configuration associated to cycle i at moment } S^{-}\end{array}$ \\
\hline$C_{b c}^{\min }$ & $\begin{array}{l}\text { Minimal value of } \\
\text { capacitance } C_{b c}\end{array}$ & $Q_{r e s}^{S^{-}, i}$ & $\begin{array}{l}\text { Electrical charges in } C_{\text {res }} \text { in the series } \\
\text { configuration associated to cycle } i \text { at moment } S^{-}\end{array}$ \\
\hline$C_{e q}$ & $\begin{array}{l}\text { Equivalent capacitance } \\
\qquad C_{e q}=\frac{C_{b c}^{M a x} \cdot C_{r e s}}{C_{b c}^{M a x}+C_{r e s}}\end{array}$ & $Q_{\text {tot }}^{S, i}$ & $\begin{array}{l}\text { Total charge in the system }\left(C_{b a}, C_{b c}, C_{r e s}\right) \\
\text { associated to cycle } i \text { at the steady state of the } \\
\text { series configuration }\end{array}$ \\
\hline$Q_{b a}$ & $\begin{array}{l}\text { Charge associated to } \\
\text { capacitor } C_{b a}\end{array}$ & $Q_{t o t}^{S^{+}, i}$ & $\begin{array}{l}\text { Total charge in the system }\left(C_{b a}, C_{b c}, C_{r e s}\right) \\
\text { associated to cycle } i \text { at the moment } S^{+} \text {of the }\end{array}$ \\
\hline
\end{tabular}




\begin{tabular}{|c|c|c|c|}
\hline & & & series configuration \\
\hline$Q_{b c}$ & $\begin{array}{l}\text { Charge associated to } \\
\text { capacitor } C_{b c}\end{array}$ & $\Delta Q^{S, i}$ & Electrical charges generated at each cycle $i$ \\
\hline Qres & $\begin{array}{l}\text { Charge associated to } \\
\text { capacitor } C_{\text {res }}\end{array}$ & $Q_{\text {tot }}^{P^{-}, i}$ & $\begin{array}{l}\text { Total charge in the system }\left(\begin{array}{lll}C_{b a}, & C_{b c}, & C_{\text {res }}\end{array}\right) \\
\text { associated to cycle } i \text { at the moment } P^{-}\end{array}$ \\
\hline$S_{b a}$ & $\begin{array}{l}\text { Electrode's contact } \\
\text { area associated to } C_{b a}\end{array}$ & $Q_{\text {tot }}^{P, i+1}$ & $\begin{array}{l}\text { Total charge in the system }\left(C_{b a}, C_{b c}, C_{\text {res }}\right) \\
\text { associated to cycle } i+1 \text { at the moment } P\end{array}$ \\
\hline$S_{b c}$ & $\begin{array}{l}\text { Electrode's contact } \\
\text { area associated to } C_{b c}\end{array}$ & $Q_{t o t}^{P^{+}, i+1}$ & $\begin{array}{l}\text { Total charge in the system }\left(\begin{array}{lll}C_{b a}, & C_{b c}, & C_{r e s}\end{array}\right) \\
\text { associated to cycle } i+1 \text { at the moment } P^{+}\end{array}$ \\
\hline$i$ & $\begin{array}{l}\text { Number of mechanical } \\
\text { cycle }\end{array}$ & $E$ & Converted energy per cycle \\
\hline$S$ & $\begin{array}{l}\text { Indicates series } \\
\text { configuration }\end{array}$ & $\sigma_{b a}$ & $\begin{array}{l}\text { Surface charge density of the triboelectric patch } \\
\text { associated to the electrode }(B / A)\end{array}$ \\
\hline$P$ & $\begin{array}{l}\text { Indicates parallel } \\
\text { configuration }\end{array}$ & $\sigma_{b c}$ & $\begin{array}{l}\text { Surface charge density of the triboelectric patch } \\
\text { associated to the electrode }(B / C)\end{array}$ \\
\hline$S^{-}$ & $\begin{array}{l}\text { Moment just before } \\
\text { contact } S_{3} \text { is ON }\end{array}$ & $\Delta Q_{b a}^{t}$ & $\begin{array}{l}\text { Triboelectric charges associated to the coupled } \\
\text { of electrode }(B / A)\end{array}$ \\
\hline$S^{+}$ & $\begin{array}{l}\text { Moment just after } \\
\text { contact } S_{3} \text { is ON }\end{array}$ & $\Delta Q_{b c}^{t}$ & $\begin{array}{l}\text { Triboelectric charges associated to the coupled } \\
\text { of electrode }(B / C)\end{array}$ \\
\hline
\end{tabular}

\section{Triboelectric enhancement}

To improve the device performances and to electrically isolate the electrodes when they are in contact, we proposed to cover the active areas of the central electrode with triboelectric patches made of Polypropylene $(P P)$. At each contact with the counterpart fixed electrodes, made of steel, the triboelectric patches produce an additional amount of charges that will speed-up the charging of the reservoir capacitor. These triboelectric charges associated to each couple of electrode $(B / A)$ and $(B / C)$ are denoted by $\Delta Q_{b a}^{t}$ and $\Delta Q_{b c}^{t}$, respectively. They are approximated by [32]:

$$
\Delta Q_{b a}^{t} \approx \frac{2 \sigma_{b a} S_{b a}}{1+\frac{c_{b c}^{\min }}{c_{b a}^{M a x}}} \text { and } \Delta Q_{b c}^{t} \approx \frac{2 \sigma_{b c} S_{b c}}{1+\frac{c_{b a}^{\min }}{c_{b c}^{M a x}}}
$$

where $S_{b a}$ and $S_{b c}$ are the electrode's contact area associated to $C_{b a}$ and $C_{b c}, \sigma_{b a}$ and $\sigma_{b c}$ being the surface charge densities of each patch.

\section{Time evolution of electrical quantities}

From the previous analysis, we can simulate the electrical evolution of the system for 
multiple oscillations of the movable electrode $B$. We assume that $C_{b a}$ and $C_{b c}$ are perfectly symmetrical and out of phase, both of them varying between $C_{\min }$ and $C_{\text {Max }}$. Firstly, we do not take into account the triboelectric charges and we assume that the switches are ideal without any ohmic losses. Therefore the variation of charge per mechanical cycle given by Eq.(10) becomes:

$\Delta Q^{S, i}=V^{P, i} \frac{\left(C_{M a x}{ }^{2}-C_{M a x} C_{\min }-C_{\min }{ }^{2}\right) C_{r e s}}{C_{\text {Max }}\left(C_{\min }+2 C_{r e s}\right)}=\alpha V^{P, i}$

For the numerical calculation we set $C_{\min }=20 \mathrm{pF}$ and $C_{\text {res }}=10 \mathrm{nF}$. Fig. $2 \mathrm{a}$, shows the variation of $\tilde{\alpha}$ ( $\alpha$ normalized with $C_{\min }$ ) versus the capacitance ratio $\eta=C_{\operatorname{Max}} / C_{\min }$. To convert electrical energy from the mechanical domain, $\Delta Q^{S, i}$ and then $\tilde{\alpha}$, have to be positive. This corresponds to $\eta>1.619$. Fig. $\mathbf{2 b}$ shows $V_{\text {res }}$ versus $\eta$ after 2000 cycles. Fig. $\mathbf{2 c}$ and $\mathbf{2 d}$ show the harvested energy $E$ during the $2000^{\text {th }}$ cycle versus $\eta$ and $V_{\text {res }}$ (with $\eta=4$ ), respectively.

Fig. $2 \mathrm{e}$ and 2 .f show the positive influence of the triboelectric charge regarding the output voltage $V_{\text {res }}$ and the harvested energy $E$ at each cycle, respectively. $\eta$ is set to 4 and the initial voltage due to the electromagnetic ambient (EM) noise $V_{0}=1 \mathrm{~V}$. The surface density of the triboelectric layer is set to $\sigma_{b a}=\sigma_{b c}=210^{-6} \mathrm{C} / \mathrm{m}^{2}$ [32] and the contact surface $S_{b a}=$ $S_{b c}=12 \mathrm{~cm}^{2}$.

As for any kinetic energy harvester based on gap-closing geometry, the level of converted energy is strongly related to the capacitance ratio $\eta=C_{\operatorname{Max}} / C_{\min }$ : the system is more efficient for large ratio $\eta$. In addition, the triboelectric patches bring a very positive influence since they allow to speed-up the energy conversion process and allow the system to start from electromagnetic ambient charges. These impact of the triboelectric patches become negligible for higher cycles as seen in Fig. 2e and 2.f. 
a.

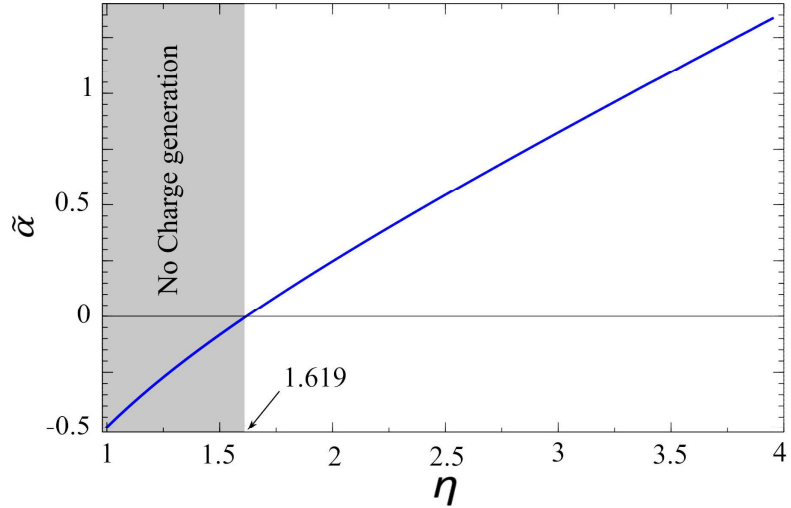

c.

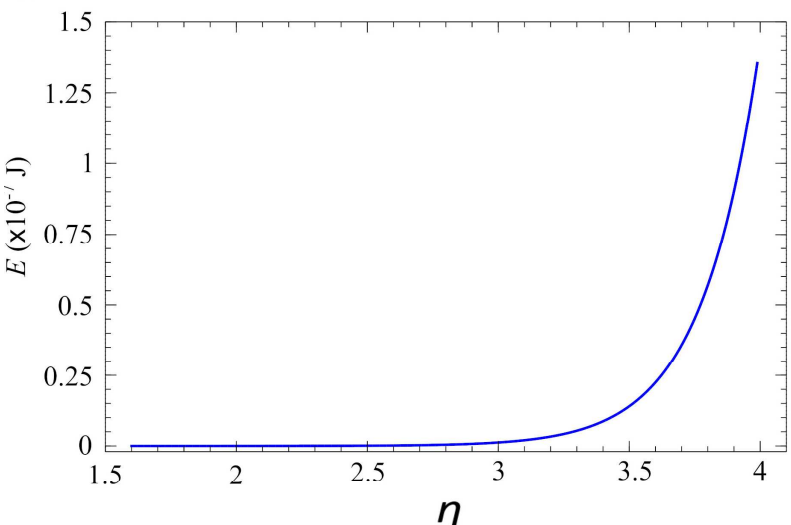

e.

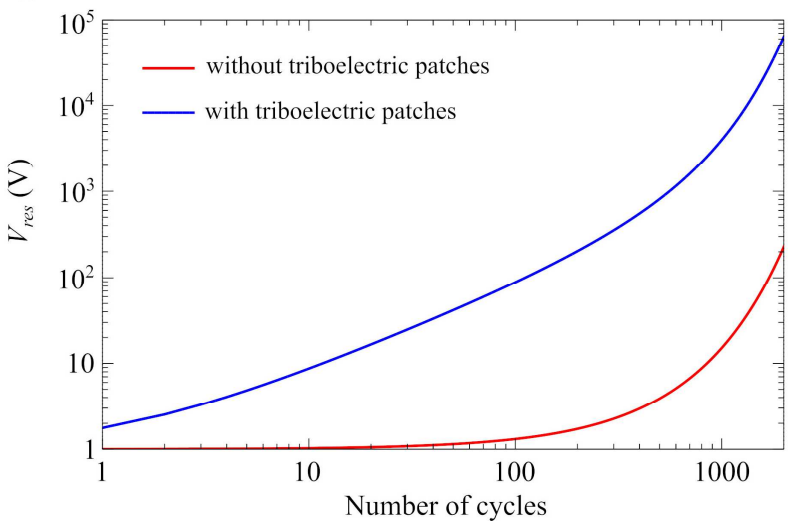

b.

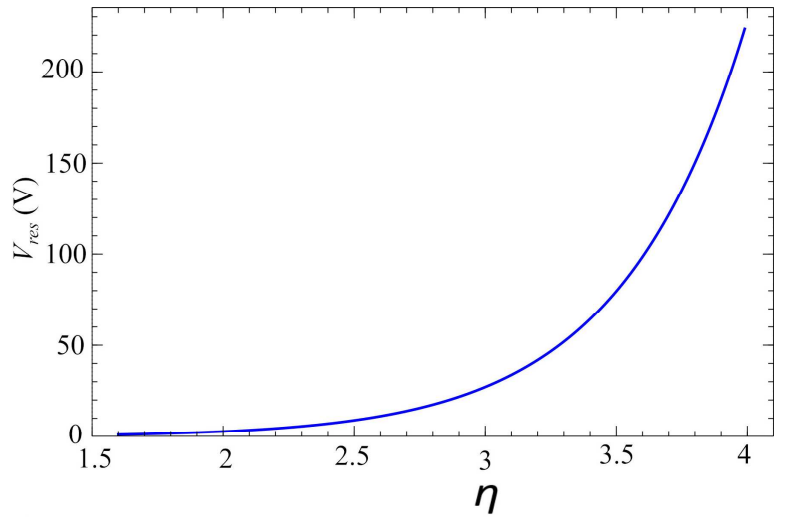

d.

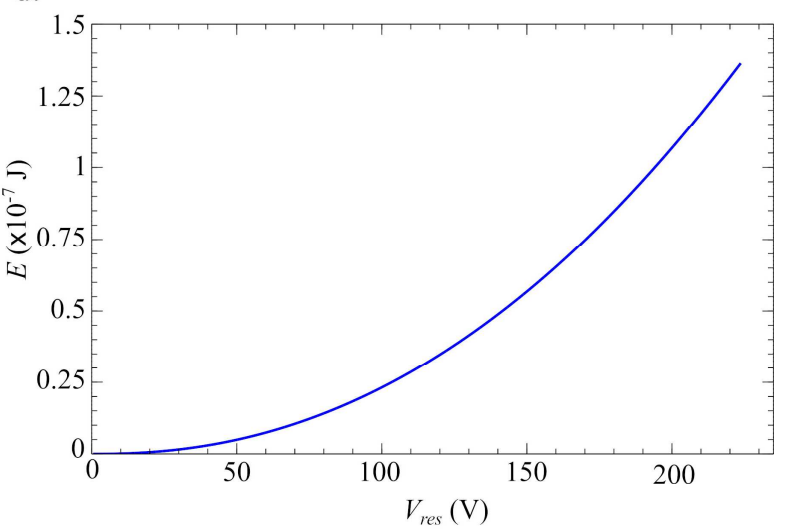

f.

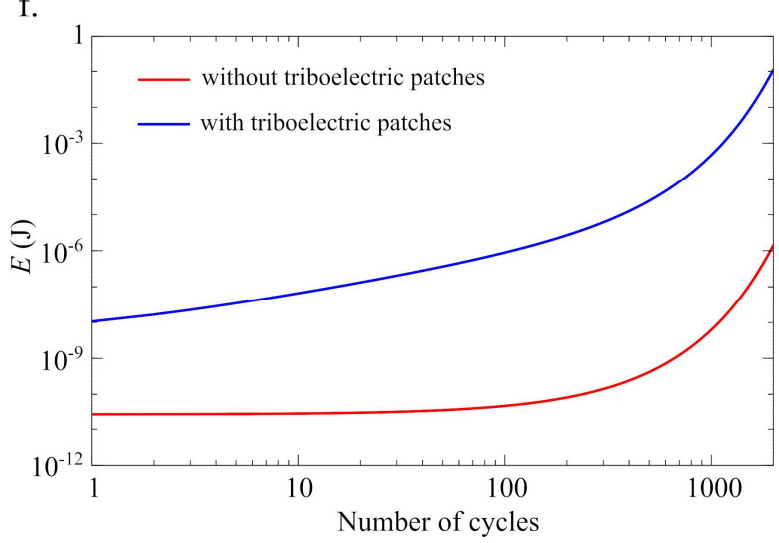

Fig. 2. Evolutions of the electrical quantities. a. Variation of $\tilde{\alpha}$ ( $\alpha$ normalized with $C_{\min }$ ) versus the capacitance ratio $\eta$. b. Variation of $V_{\text {res }}$ and $\mathbf{c}$. variation of the energy $E$ versus $\eta$. d. Variation of the energy $E$ versus $V_{\text {res }}$ for $\eta=4$ at the $2000^{\text {th }}$ cycle. e. Variation of the $V_{\text {res }}$ after $10000^{\text {th }}$ cycle and $\mathbf{f}$. Evolution of the energy $E$ versus the number of cycles when triboelectric patches are added.

\section{Modelling of the electromechanical system}

The proposed electrostatic generator consists on a movable electrode $B$ having an inertial masse $m$ free to move thanks to a linear bearing as shown in Fig. 3a. The electrode $B$ is excited when an external acceleration, that we consider harmonic, is applied on the rigid 
frame. The displacement of $B$ is limited by the switches $S_{1}$ and $S_{3}$ that act as rigid and damped stoppers at positions $x_{01}$ and $x_{03}$ respectively. $S_{2}$ is a flexible stopper.

In this section, the full model for the generator is detailed, including the coupling of the Modelling of the full system under external excitation.

According to the second Newton law, the behaviour of the generator (Fig. 3a) is given by:

$$
\left\{\begin{array}{cc}
m \ddot{x}+c \dot{x}=m \gamma+F_{b a}+F_{b c} & \text { for } \mathrm{x}_{02}<\mathrm{x} \leq \mathrm{x}_{03} \\
m \ddot{x}+\left(c+c_{2}\right) \dot{x}+k_{2}\left(x-x_{02}\right)=m \gamma+F_{b a}+F_{b c} & \text { for } \mathrm{x}_{01} \leq \mathrm{x} \leq \mathrm{x}_{02}
\end{array}\right.
$$

where $x$ and $\dot{x}$ are the displacement and the velocity of electrode $\mathrm{B}$ respectively, $c$ represents the mechanical damping coefficient due to friction and $\gamma$ is the external applied acceleration. $F_{b a}$ and $F_{b c}$ are the electrostatic force associated to the variable capacitances $C_{b a}$ and $C_{b c}$ given by:

$$
F_{b a}=\frac{1}{2} \frac{d C_{b a}}{d x}\left(\frac{Q_{b a}}{C_{b a}}\right)^{2}=\frac{1}{2} \frac{d C_{b a}}{d x}\left(V_{b a}\right)^{2}, \quad F_{b c}=\frac{1}{2} \frac{d C_{b c}}{d x}\left(\frac{Q_{b c}}{C_{b c}}\right)^{2}=\frac{1}{2} \frac{d C_{b c}}{d x}\left(V_{b c}\right)^{2}
$$

where $C_{b a}=\frac{\varepsilon S_{b a}}{d_{0}+x}$ and $C_{b c}=\frac{\varepsilon S_{b c}}{d_{0}-x} . Q_{b a}, V_{b a}, Q_{b c}$ and $V_{b c}$ are the electrical charges and electrical potential associated to the capacitor $C_{b a}$ and $C_{b c}$ respectively. $\varepsilon$ is the vacuum permittivity and $d_{0}$ the electrostatic gap distance shown in Fig. $3 a$.

At each contact between the electrode $B$ and $A$ or $C$, a bouncing phenomenon takes place and the electrode $B$ losses some of its kinetic energy. Their velocities are changed, at the contact moment, according to [34]

$$
\begin{cases}\dot{x} \leftarrow-\beta_{b a} \dot{x} & \text { when } \mathrm{x}=\mathrm{x}_{01} \\ \dot{x} \leftarrow-\beta_{b c} \dot{x} & \text { when } \mathrm{x}=\mathrm{x}_{03}\end{cases}
$$

The restitution coefficient $\beta_{b a}$ and $\beta_{b c}$ will be determined by fitting the results with experimental data. When the masse reaches its position $x_{02}$, a repulsive force with stiffness $k_{2}$ and a damping coefficient $c_{2}$ are added.

\section{Modelling of the electrical system}

In the previous section, the switches were modelled as perfect switches but they actually have a small contact resistance. In this section, we use a more realistic model, where the ohmic contacts are denoted by $R_{1,2,3}$ for the switches $S_{1,2,3}$ (see Fig. 3 ). As the electrode $B$ is moving, the electric system varies due to activation of different switches. In the following, we describe mathematically the different circuits connecting the system's components.

Electrode $B$ is between $x_{02}$ and $x_{01}$

Before being in contact with electrode $A$, the switch $S_{2}$ is ON while $S_{1}$ and $S_{3}$ are OFF (Fig. 
3b). The equations describing the electrical system are given by:

$$
\left\{\begin{array}{l}
V_{b a}=V_{\mathrm{bc}}+R_{2} \frac{d\left(C_{b c} \mathrm{~V}_{\mathrm{bc}}\right)}{d t} \\
\frac{d\left(C_{b a} \mathrm{~V}_{\mathrm{ba}}\right)}{d t}+\frac{d\left(C_{b c} \mathrm{~V}_{\mathrm{bc}}\right)}{d t}=0
\end{array}\right.
$$

When the electrode $B$ reaches the electrode $A$ at position $x_{01}$, the mechanical switches $S_{1}$ turns ON leading to the parallel configuration of Fig. 3c. The contact between the two electrodes adds a triboelectric charge $\Delta Q_{b a}^{t}$ to the system. The capacitance $C_{b a}$ is at its maximum value $C_{b a}^{M a x}$ and $C_{b c}$ at its minimum value $C_{b c}^{\min }$. The equations describing the electrical system are given by:

$$
\left\{\begin{array}{l}
V_{b a}=V_{\mathrm{res}}+R_{1} C_{r e s} \frac{\mathrm{dV}_{\text {res }}}{\mathrm{dt}} \\
V_{b a}=V_{\mathrm{bc}}+R_{2} \frac{d\left(C_{b c} \mathrm{~V}_{\mathrm{bc}}\right)}{d t} \\
\frac{d\left(C_{b a} \mathrm{~V}_{\mathrm{ba}}\right)}{d t}+\frac{d\left(C_{b c} \mathrm{~V}_{\mathrm{bc}}\right)}{d t}+C_{r e s} \frac{\mathrm{dV}_{\text {res }}}{\mathrm{dt}}=0
\end{array}\right.
$$

where $V_{\text {res }}$, is the voltage across $C_{\text {res }}$.

\section{Electrode $B$ is between $x_{02}$ and $x_{03}$}

When $B$ moves between $x_{02}$ and $x_{03}$ (Fig. $3 \mathrm{~d}$ ), all switches are OFF. The mobile electrode is isolated and all charges remain constant. The voltages across the capacitances become:

$$
\left\{\begin{array}{l}
V_{\text {res }}=\frac{Q_{\text {res }}}{C_{\text {res }}} \\
V_{\mathrm{ba}}=\frac{Q_{\mathrm{ba}}}{C_{b a}} \\
V_{\mathrm{bc}}=\frac{Q_{\mathrm{bc}}}{C_{b c}}
\end{array}\right.
$$

When $B$ is in contact with $C, S_{3}$ becomes $\mathrm{ON}$ and all the capacitors are in series (Fig. 3e). The induced impact adds a triboelectric charge $\Delta Q_{b c}^{t}$ to the system, and the electrical equations associated to the series configuration are given by:

$$
\left\{\begin{array}{l}
V_{\text {res }}+R_{3} i+V_{b c}-V_{b a}=0 \\
i=-\frac{d\left(C_{b a} V_{b a}\right)}{d t}=\frac{d\left(C_{b c} V_{b c}\right)}{d t}=C_{r e s} \frac{\mathrm{d} V_{r e s}}{\mathrm{dt}}
\end{array}\right.
$$



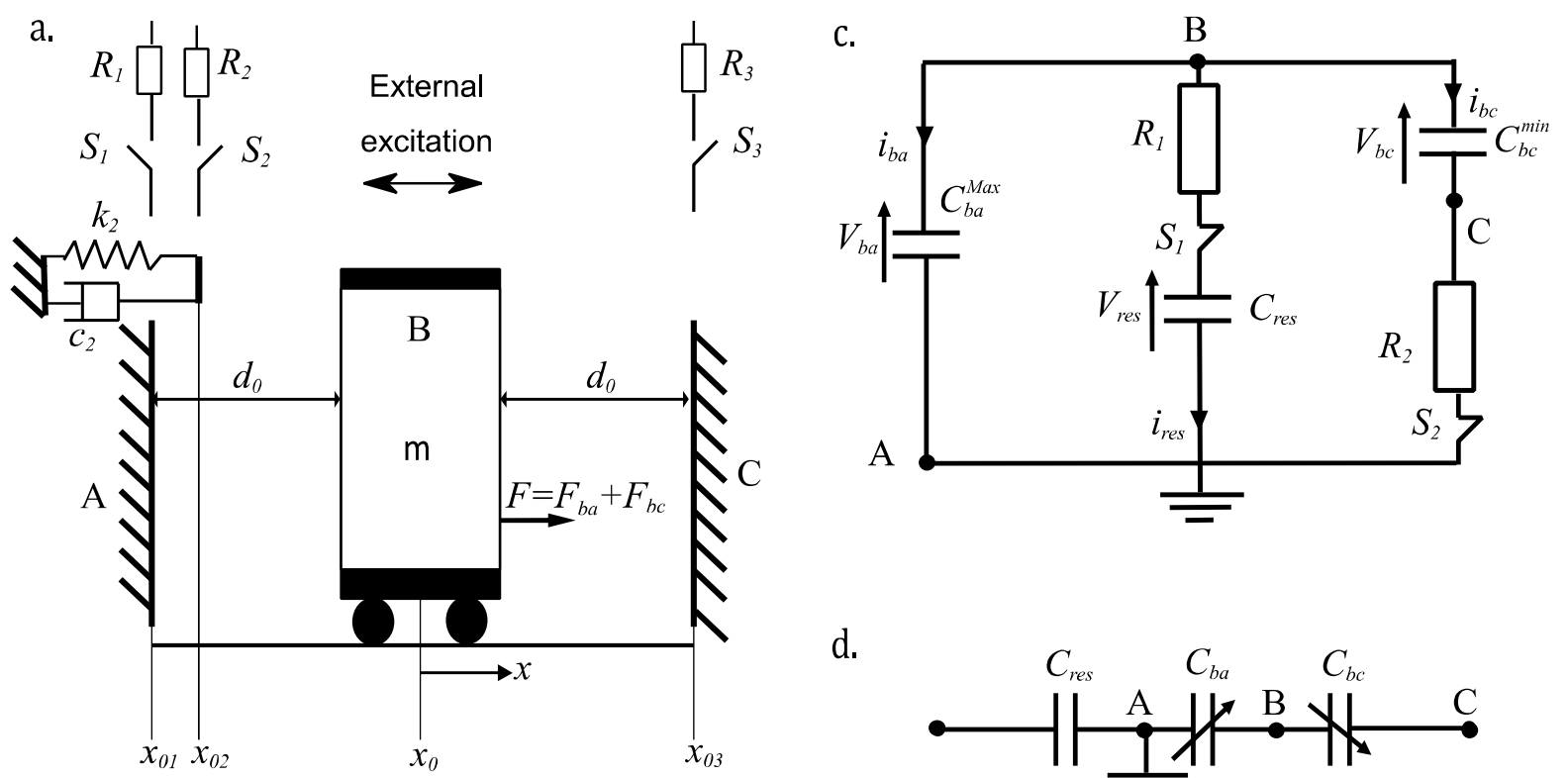

b.

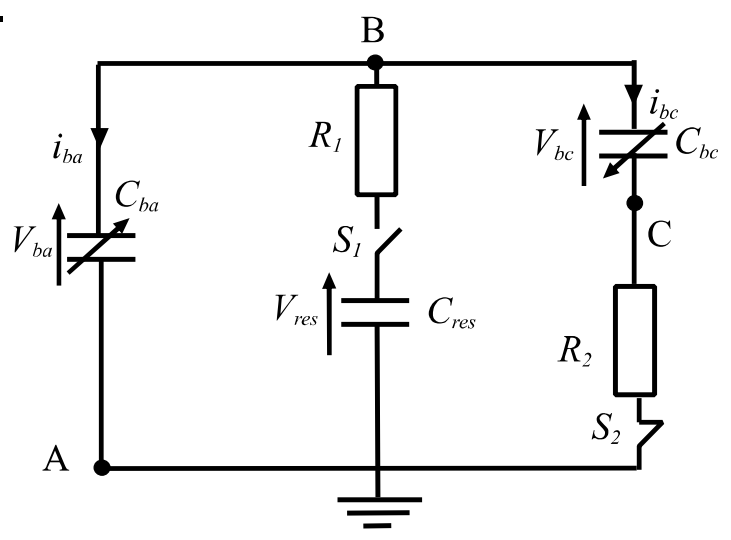

d.

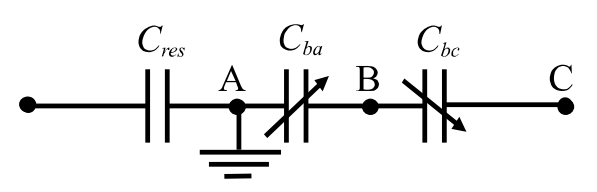

e.

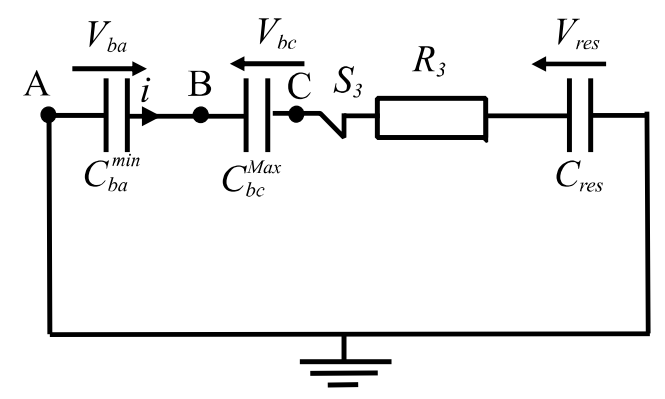

Fig. 3. Electromechanical model of the system a. Mechanical representation. b. Equivalent circuit between $x_{01}$ and $x_{02}$. c. Equivalent circuit at $x_{01}$ (parallel configuration) d. Equivalent circuit between $x_{02}$ and $x_{03}$. e. Equivalent circuit at $x_{03}$ (series configuration).

\section{Description of the electromechanical system}

The mechanical model given by Eq.(17) depends on the electrostatic forces $F_{b a}$ and $F_{b c}$, which can be calculated from voltages defined in the electrical model in equations Eq.(20), Eq.(21), Eq.(22) and Eq.(22). To solve this electromechanical coupled system, we use a onestep Finite Difference (FD) forward scheme with a time step $\Delta t . x_{j}$ and $\dot{x}_{j}$ represent the position and velocity at time $j \Delta t$. The detailed algorithm is described in Fig. 4. 


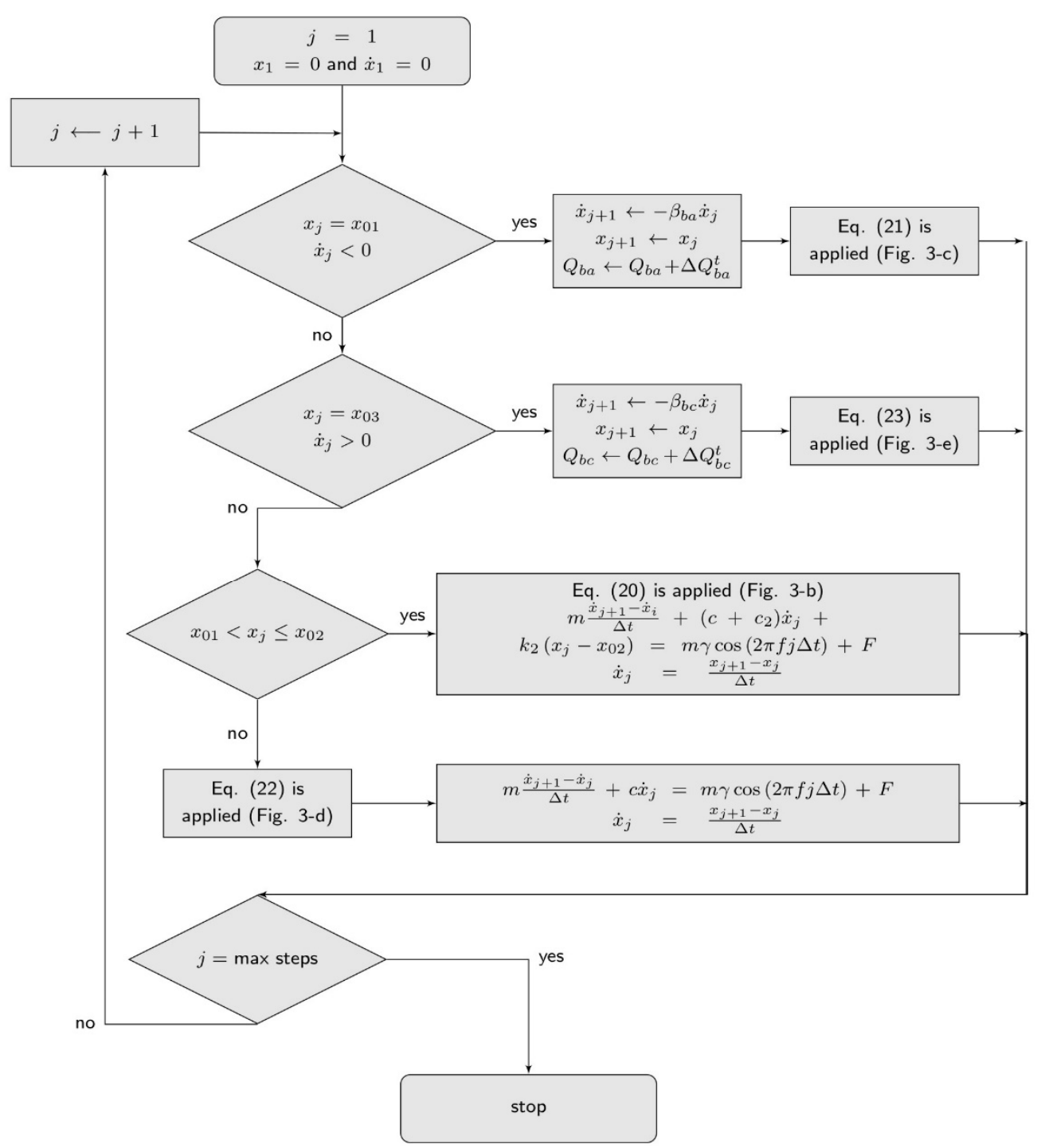

Fig. 4. Flow chart of the proposed algorithm for modelling the electromechanical system.

\section{Coupled simulations, experiments results and discussions:}

1. Experimental setup and capacitance variations:

The fabricated proof-of-concept generator is shown in Fig. 5a. Electrodes are made of steel. Polyamide is used for the frame to ensure electrical insulation between different parts. Low friction of the moving central electrode $B$ is obtained thanks to a linear bearing. For the triboelectric charge generation, Polypropylene (PP) patches of $50 \mu \mathrm{m}$ in thickness covers the active areas of electrode $B$. The generator is mounted on a shaker (LDS V40b from Brüel \& Kjaer) where harmonic excitations are applied (Fig. 5b). The vibrations are controlled by a servo system (model 7541 from B\&K) and by an accelerometer (model 4507B004 from B\&K). 
A setup is used to measure the variations of the capacitances $C_{b a}$ and $C_{b c}$ using a phaseshift measurement between two signals in the $R C$ circuit presented in Fig. 5c [35]. For each phase shift $\theta$, the capacitance is calculated as:

$$
C_{b a, b c}=\frac{1}{\tan (\theta) R_{b a, b c} \omega}
$$

where $\omega$ is the angular frequency of $V_{a c}$ and $\theta$ represents the phase shift between the voltage across the variable capacitor and the voltage of excitation source.

The value of the resistance has to be carefully chosen to maximize the sensitivity at the frequency of interest. Best accuracy is obtained for a phase-shift of $\pi / 4$, i.e. for $R_{b a, b c} C_{b a, b c} \omega=$ 1 [36]. So that, $R_{b a, b c}$ is set as follow:

$$
R_{b a, b c}=\frac{1}{C_{b a, b c}^{a v} \omega}
$$

where the average values $C_{b a, b c}^{a v}$ are defined as:

$$
C_{b a, b c}^{a v}=\frac{C_{b a, b c}^{\operatorname{Max}}+C_{b a, b c}^{\min }}{2}
$$

$C_{b a, b c}^{M a x}$ and $C_{b a, b c}^{\min }$ are first measured with an RLC impedance-meter. The dynamic capacitance measurements are performed with a $5 \mathrm{~Hz}$ excitation at $0.2 \mathrm{grms}_{\mathrm{rm}} V_{a c}$ is set to $1.5 \mathrm{~V}$ peak-topeak and its frequency is set to $100 \mathrm{KHz}$.

\section{Model validation:}

The measured values of both capacitances are shown in Fig. $5 d$ and Fig. 5e. Using the derived electromechanical model in Eq.(17), with the physical and geometrical parameters presented in [37], we fit the numerical results of the capacitances with those measured experimentally by adjusting the restitution and damping coefficients. Fig. $5 d$ and Fig. $5 e$ show a good agreement between the measured and predicted capacitances variation over time at steady state. We observe an asymmetry between $C_{b a}$ and $C_{b c}$ due to some inaccuracy in the device fabrication: $C_{b a}$ varies between $C_{b a}^{M a x}=210 p F$ and $C_{b a}^{\min }=20 p F$, while $C_{b c}$ varies between $C_{b c}^{M a x}=170 p F$ and $C_{b c}^{\text {min }}=30 p F$. 
a.

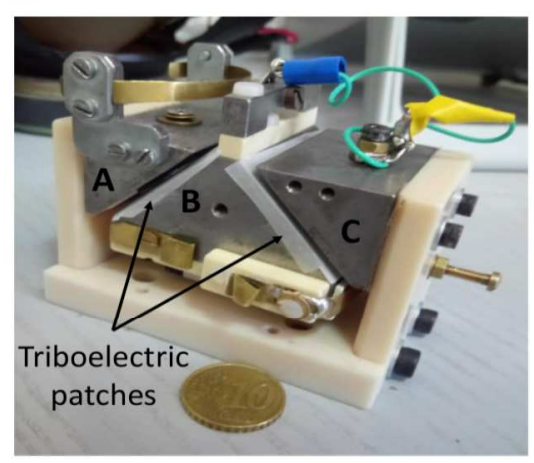

d.

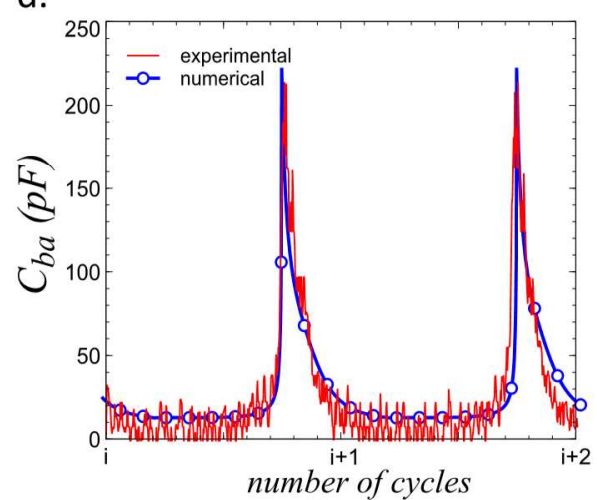

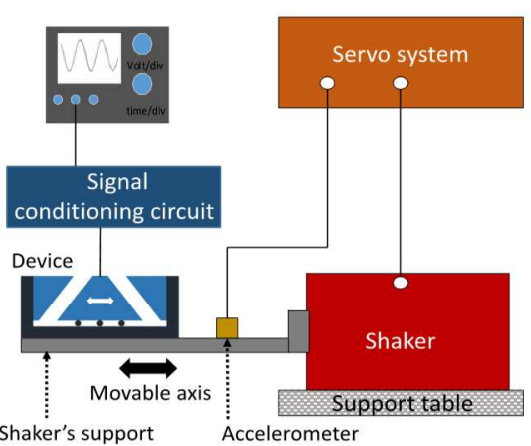

C.

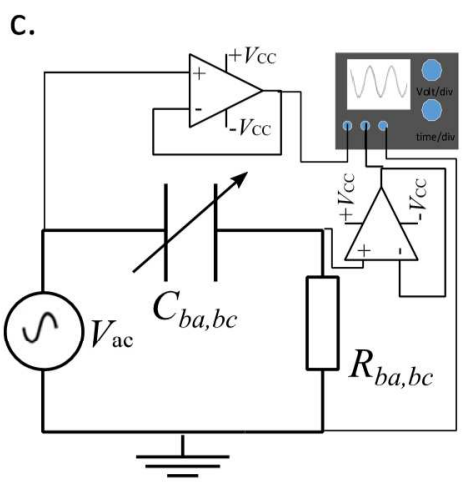

e.

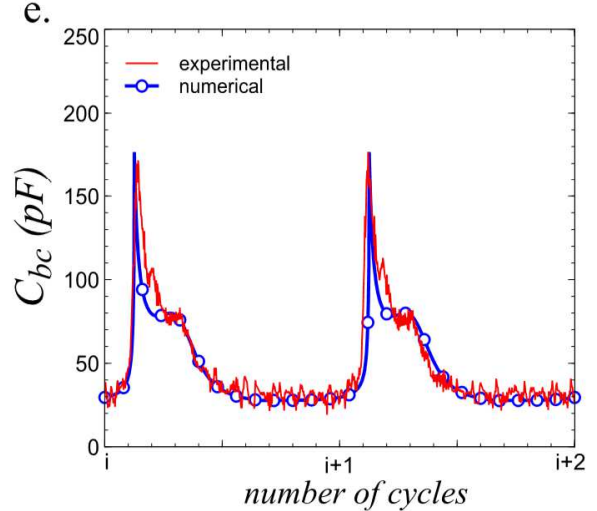

Fig. 5. Description of the experimental setup. a. Fabricated generator. b Setup and test bench representation . c. Circuit for measuring the capacitances $C_{b a}$ and $C_{b c}$. d. Evolution of $C_{b a}$ (experiment and model). e. Evolution of $C_{b c}$ (experiments and model).

Table 2. Geometrical and electrical parameters of the generator

\begin{tabular}{|c|l|c|}
\hline Variable & \multicolumn{1}{|c|}{ Significations } & Value \\
\hline$C_{r e s}$ & Storage capacitance & $9.68 \mathrm{nF}$ \\
\hline$R_{1}, R_{2}, R_{3}$ & Contact resistance (evaluated) & $0.1 \Omega$ \\
\hline$x_{0}$ & Initial position & $0 \mathrm{~mm}$ \\
\hline$x_{01}$ & Position of $S_{1}$ & $1.95 \mathrm{~mm}$ \\
\hline$x_{02}$ & Position of $S_{2}$ & $-1.4 \mathrm{~mm}$ \\
\hline$x_{03}$ & Position of $S_{3}$ & $-1.95 \mathrm{~mm}$ \\
\hline$m$ & Inertial mass of electrode B & $315 \mathrm{mg}$ \\
\hline$f$ & Excitation frequency & $5 \mathrm{~Hz}$ \\
\hline$\gamma$ & External acceleration & $0.2 \mathrm{grms}$ \\
\hline$k_{2}$ & Stiffness of $S_{2}$ (estimated using finite element) & $200 \mathrm{~N} / \mathrm{m}$ \\
\hline$c_{2}$ & Damping coefficient (fitted) & $0.2 \mathrm{~N} . \mathrm{s} / \mathrm{m}$ \\
\hline$\beta_{\mathrm{bc}}$ & Restitution coefficient when contact with C (fitted) & 0.15 \\
\hline$\beta_{\mathrm{ba}}$ & Restitution coefficient when contact with A (fitted) & 0.09 \\
\hline$\Delta t$ & Time step & $0.4 \mathrm{~ms}$ \\
\hline$\sigma_{b a}=\sigma_{b c}$ & Triboelectric surface charge density Polypropylene (PP) & $2 \times 10^{-6} \mathrm{C} / \mathrm{m}{ }^{2}$ \\
\hline$S_{b a}=S_{b c}$ & Active area of each side of electrode $B$ & $1.2 \times 10^{-3} \mathrm{~m}^{2}$ \\
\hline & & \\
\hline
\end{tabular}




\section{Device performances}

Once all the parameters of the derived electromechanical model are set, we can model the harvested energy and compare with the experimental results. $V_{\text {res }}$ is measured with a capacitive divider due to its high value, and after a high-impedance follower (Fig. 6a). Experimentally, the shaker vibrations are set to $5 \mathrm{~Hz}$ with $0.2 \mathrm{~g}_{\mathrm{rms}}$. Then starting from electromagnetic (EM) ambient noise and measuring the evolution of $V_{\text {res, }}$, we show in Fig. $\mathbf{6 d}$ the variations of $V_{\text {res }}$ over the increasing number of oscillation cycles. A good concordance is observed between numerical model and experimental tests, also presented as an approximated function using a polynomial fitting. One can observe that $V_{\text {res }}$ increases exponentially until a saturation phenomenon limits the voltage at $V_{\text {sat }}=416 \mathrm{~V}$. This saturation can be explained by the increase of the total effective electrostatic force $F=F_{b a}+F_{b c}$ becoming higher than the inertial force and inducing a spring-softening effect [20]. A zoom of the displacement of electrode $B$ is depicted in Fig. 6c. One can observed a drastic diminution of the oscillation at $n_{\text {sat }}=718$ cycles until the electrode $\mathrm{B}$ is immobilized close to the electrode A. This is confirmed by the variation of the total effective electrostatic force $F$ shown in Fig. 6b. Fig. 6e shows the evolution of the energy at each cycle versus the number of cycles (using the fitted voltage function) and Fig. $6 \mathrm{f}$ shows the time evolution of the accumulated energy in $C_{\text {res: }}$ about $.9 \mathrm{~mJ}$ are available after $2.5 \mathrm{~min}$. The Influence of the initial pre-charge on $C_{\text {res }}$ is also showed in Fig. $\mathbf{6 g}$.

\section{Influence of the triboelectric patch}

We have compared different triboelectric patches materials and their respective thicknesses on the generator performance. Firstly, we did experiments with polypropylene (PP) and Teflon (PTFE) having the same thickness of $50 \mu \mathrm{m}$. As expected, PTFE gave better results because of its better charge affinity $(-190 \mathrm{nC} / J$ for PTFE and $-90 \mathrm{nC} / J$ for PP), as shown in Fig. 6h. Then we varied the patch thickness (Fig. 6i) for the PTFE. It is clear that less thickness gives more energy: the maximum value of the gap-closing capacitances $C_{b a}^{M a x}$ and $C_{b c}^{\operatorname{Max}}$ becomes more important since the gap distance is lower. 
a.
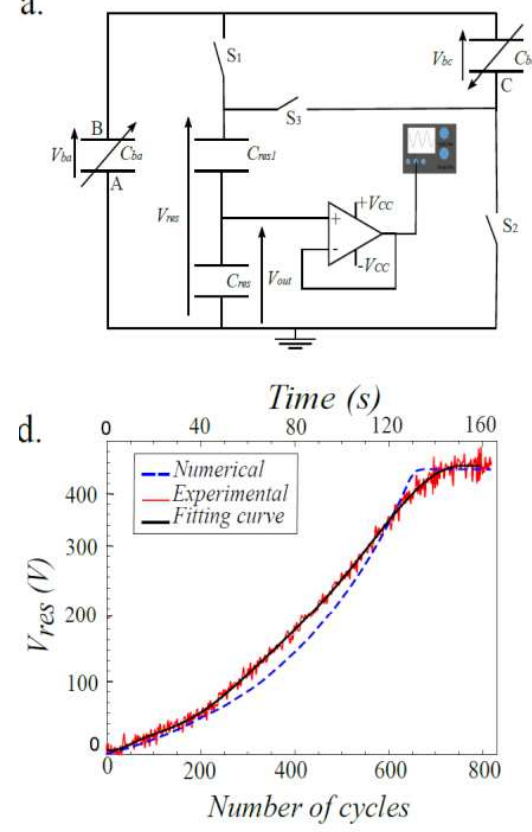

g.

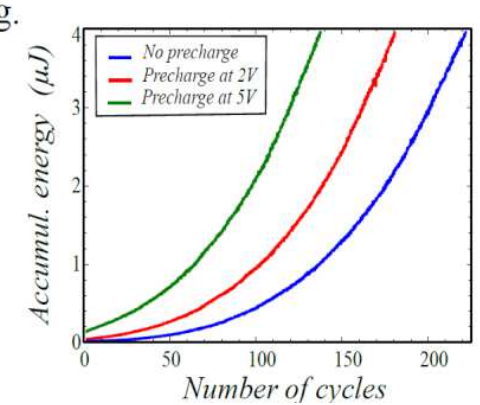

b.

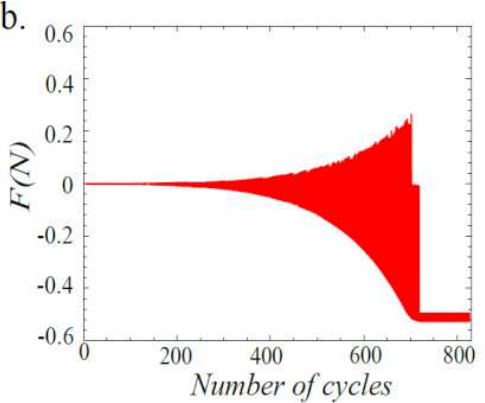

e.

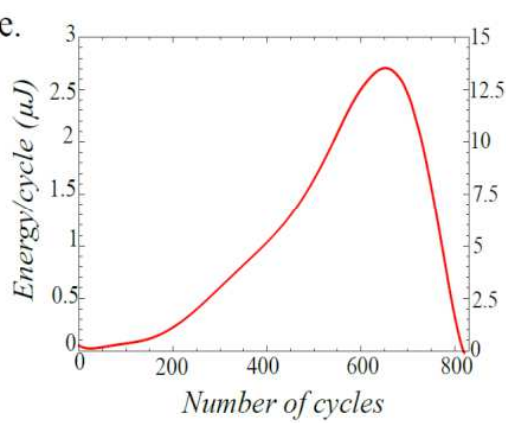

h.

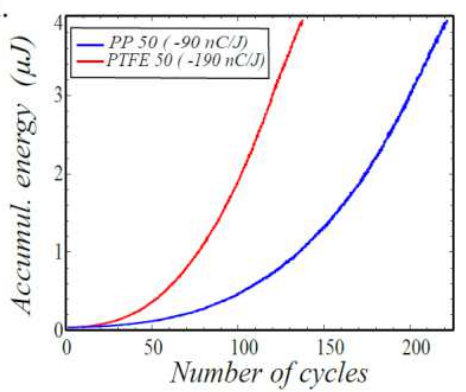

c.

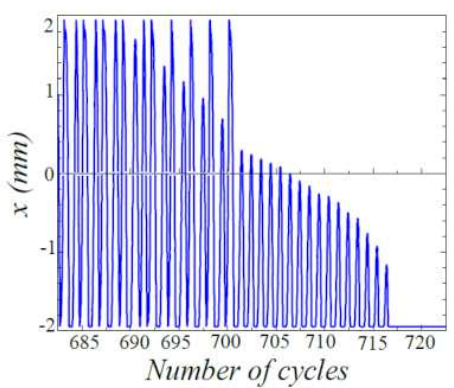

f.
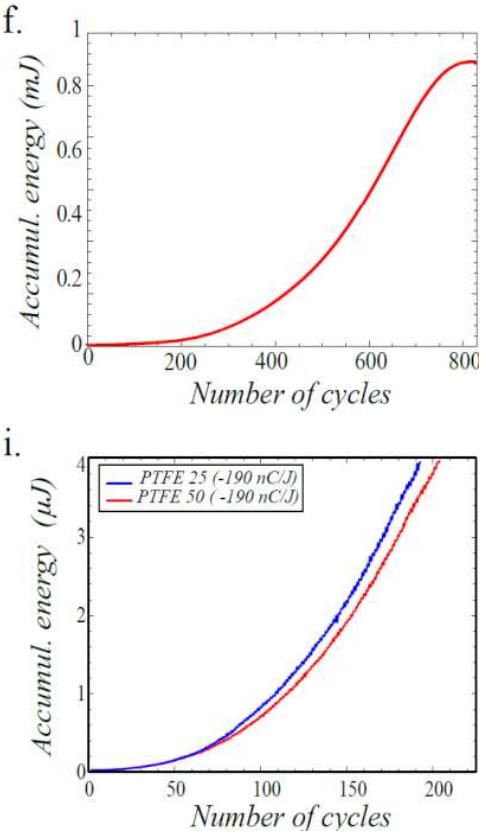

Fig. 6. Experimental results. a. Circuit used to perform the measurements. b. Evolution of the electrostatic force applied on electrode B. c. Zoom of displacement of electrode B when saturation occurs. d. Evolution of the output rectified voltage with number of cycles and time (numerical and measurement). e. Evolution of the harvested energy with number of cycles. f. Accumulated energy in the output capacitance. $g$. Influence of the initial pre-charge on $\boldsymbol{C}_{\text {res. }} . \mathbf{h}$. Influence of the patch triboelectric charge density. i. Influence of the triboelectric patch thickness.

\section{Conclusion}

In this paper, a new triboelectric nanogenerator having an exponential increase with time of the converted energy from the mechanical-to-electrical domains has been proposed. This is obtained thanks to a self-actuated alternation between series and parallel modes of the capacitances in the system, in order to obtain a behaviour inspired by of the electrostatic machine from the $18^{\text {th }}$ century known as the "Bennet doubler". The device use only mechanical switches and takes benefit of the triboelectric effect and electrostatic induction. All the charges are stored into an external capacitor and the output signal is rectified without the need of diodes. This is the first time that such kind of electrostatic machine is used for 
vibration energy harvesting.

A prototype has been fabricated that shows an output voltage increasing exponentially until $400 \mathrm{~V}$ when vibrations of $0.2 \mathrm{~g}_{\mathrm{rms}}$ are applied, corresponding to a maximum conversion of $2.8 \mu \mathrm{J}$ per mechanical cycle, and $0.9 \mathrm{~mJ}$ are accumulated in $150 \mathrm{sec}$. After 600 cycles, a saturation occurs, which is known as the "spring softening effect" and corresponding when the electrostatic force becomes so high that it limits the displacement of the mobile mass induced by the vibrations. This limit can be exceeded by applying a higher input force. An electromechanical numerical model has also been developed. It has been experimentally validated and in particular, it can predict this spring softening effect.

This concept of automatic switching between the series and parallel configurations of the capacitances of the system can be applied to any TENG where the capacitance of the transducer varies with a ratio higher than 2 for a single variable capacitor [6] or a ratio of 1.6 for 2 variable capacitors with opposite phases like in this work. The absence of diodes and their unavoidable voltage threshold, combined with the boost introduced by the Bennet doubler structure, can largely improve the energy conversion efficiency of TENGs, especially during the start-up.

\section{Acknowledgment:}

The authors gratefully acknowledges the financial support via the PHC-Utique grant (\#17G1401 37140ZC).

\section{References}

[1] K. Murotani and Y. Suzuki, "MEMS electret energy harvester with embedded bistable electrostatic spring for broadband response", IOP J. Micromech. Microeng. 28 104001, 2018 DOI:/10.1088/1361-6439/aac8cc.

[2] H. Honma, H. Mitsuya, G. Hashiguchi, H. Fujita and H. Toshiyoshi, "A three-ports structure for electrostatic energy-harvester to lower constraint force and to enhance fast storage", Proc. 19th Int. Conf. on Solid-State Sensors, Actuators and Microsystems (Transducers'17), 2017 - DOI: 10.1109/TRANSDUCERS.2017.7994505.

[3] Basset, Philippe, et al. "Electrostatic vibration energy harvester with combined effect of electrical nonlinearities and mechanical impact." Journal of Micromechanics and Microengineering 24.3 (2014): 035001. DOI: 10.1088/0960-1317/24/3/035001.

[4] K. Tao, L. Tang, J. Wu, S. W. Lye, H. Chang and J. Miao, "Investigation of Multimodal Electret-Based MEMS Energy Harvester With Impact-Induced Nonlinearity", IEEE Journal of Microelectromechanical Systems, Vol. 27 , no 2, pp. 276-288, 2018 - DOI: 10.1109/JMEMS.2018.2792686.

[5] Y. Lu, F. Marty, D. Galayko, J.-M. Laheurte and P. Basset, "A power supply module for 
autonomous portable electronics: ultralow-frequency MEMS electrostatic kinetic energy harvester with a comb structure reducing air damping." Microsystems \& Nanoengineering 4 (2017): 28. DOI: 10.1038/s41378-018-0025-2

[6] P. Basset, E. Blokhina, and D. Galayko, "Electrostatic Kinetic Energy Harvesting". Hoboken, NJ, USA: Wiley, 2016 - DOI:10.1002/9781119007487. DOI: 10.1002/9781119007487.

[7] A. Kempitiya, D.-A. Borca-Tasciuc, and M. M. Hella, "Analysis and optimization of asynchronously controlled electrostatic energy harvesters," IEEE Trans. Ind. Electron., vol. 59, no. 1, pp. 456-463, 2012. DOI: 10.1109/TIE.2011.2141097.

[8] D. Galayko, A. Dudka, A. Karami, E. O’Riordan, E. Blokhina, O. Feely, and P. Basset, "Capacitive energy conversion with circuits implementing a rectangular charge-voltage cyclePart 1: Analysis of the electrical domain," IEEE Trans. Circuits Syst. I, Reg. Papers, vol. 62, no. 9, pp. 2652-2663, 2015. DOI: 10.1109/TCSI.2015.2451911.

[9] S. Boisseau, P. Gasnier, M. Gallardo, and G. Despesse, "Self-starting power management circuits for piezoelectric and electret-based electrostatic mechanical energy harvesters", J. Phys., Conf. Ser., vol. 476, no. 1, p. 012080, 2013 - DOI:10.1088/1742-6596/476/1/012080.

[10] Roundy, Shad, Paul K. Wright, and Kristofer SJ Pister. "Micro-electrostatic vibration-toelectricity converters." ASME 2002 International Mechanical Engineering Congress and Exposition. American Society of Mechanical Engineers, 2002. DOI: 10.1115/IMECE200239309.

[11] B. C. Yen, and J. H. Lang. "A variable-capacitance vibration-to-electric energy harvester." IEEE Transactions on Circuits and Systems I: Regular Papers 53.2 (2006): 288-295. DOI: 10.1109/TCSI.2005.856043.

[12] P. Basset, et al. "A batch-fabricated and electret-free silicon electrostatic vibration energy harvester." Journal of Micromechanics and Microengineering 19.11 (2009): 115025. DOI: 10.1088/0960-1317/19/11/115025.

[13] F. Xi, Y. Pang, W. Li, T. Jiang, L. Zhang, T. Guo, G. Liu, C. Zhang and Z. L. Wang, "Universal power management strategy for triboelectric nanogenerator", Nano Energy 37 (2017) 168-76. DOI: 10.1016/j.nanoen.2017.05.027.

[14] Chiu, Yi, and Victor FG Tseng. "A capacitive vibration-to-electricity energy converter with integrated mechanical switches." Journal of Micromechanics and Microengineering 18.10 (2008): 104004. DOI: 10.1088/0960-1317/18/10/104004.

[15] Samaali, H., B. Ouni, and F. Najar. "Design and modelling of MEMS DC-DC converter." Electronics Letters 51.11 (2015): 860-861. DOI: 10.1049/el.2014.4378.

[16] A. Ghaffarinejad, J. Yavand Hasani, R. Hinchet, Y. Lu, H. Zhang, A. Karami, D. Galayko, S.-W. Kim and P. Basset, "A new power management circuit with exponential enhancement of output energy in triboelectic energy harvesters", Nano Energy, vol. 51, pp. 173 - 184, 2018 - DOI: 10.1016/j.nanoen.2018.06.034

[17] A. Dudka, P. Basset, F. Cottone, E. Blokhina and D. Galayko, "Wideband electrostatic vibration energy harvester (e-veh) having a low start-up voltage employing a high-voltage integrated interface", Journal of Physics: Conference Series, 476 (1), 012127, 2013. DOI:10.1088/17426596/476/1/012127

[18] Bennet, Abraham, and Richard Kaye. "An account of a doubler of electricity, or a machine by which the least conceivable quantity of positive or negative electricity may be continually doubled, till it becomes perceptible by common electrometers, or visible in sparks. by the Rev. Abraham Bennet, MA; communicated by the Rev. Richard Kaye, LL. DFRS." Philosophical Transactions of the Royal Society of London 77 (1787): 288-296. DOI: 10.1098/rstl.1787.0027.

[19] de Queiroz, Antonio Carlos M. "Electrostatic vibrational energy harvesting using a variation of Bennet's doubler." Circuits and Systems (MWSCAS), 2010 53rd IEEE International Midwest 
Symposium on. IEEE, 2010. DOI: 10.1109/MWSCAS.2010.5548752.

[20] Dorzhiev, Vitaly, et al. "Electret-free micromachined silicon electrostatic vibration energy harvester with the Bennet's doubler as conditioning circuit." IEEE Electron Device Letters 36.2 (2015): 183-185. DOI: 10.1109/LED.2014.2387213.

[21] E. Lefeuvre, S. Risquez, J. Wei, M. Woytasik, and F. Parrain, "Selfbiased inductor-less interface circuit for electret-free electrostatic energy harvesters," in J. Phys., Conf. Series, vol. 557, p. 012052, 2014 DOI: 10.1088/1742-6596/557/1/012052.

[22] A. Karami, D. Galayko and P. Basset, "Series-parallel charge pump conditioning circuits for electrostatic kinetic energy harvesting", IEEE Transactions on Circuits and Systems I: Regular Papers, Vol. 64, no 1, pp. 227 - 240, 2017 - DOI: 10.1109/TCSI.2016.2603064

[23] Ouanes, MA Ben, et al. "Design and test of a Bennet's doubler device with mechanical switches for vibrational energy harvesting." Journal of Physics: Conference Series. Vol. 773. No. 1. IOP Publishing, 2016. DOI: 10.1088/1742-6596/773/1/012038.

[24] Cuong Phu Le and Einar Halvorsen, "MEMS electrostatic influence machines." Journal of Physics: Conference Series, vol. 773, n 11 , (2016). doi:10.1088/1742-6596/773/1/012048. DOI: 10.1088/1742-6596/773/1/012048.

[25] Fan, F.-R., Tian, Z.-Q. \& Lin Wang, Z. Flexible triboelectric generator. NanoEnergy 1, 328-334 (2012). DOI: 10.1016/j.nanoen.2012.01.004.

[26] Z. L. Wang, "On Maxwell's displacement current for energy and sensors: the origin of nanogenerators", Materials Today, 20(2): 74-82, 2017 - DOI: 10.1016/j.mattod.2016.12.001

[27] Z. L. Wang, T. Jiang and Liang $\mathrm{Xu}$, "Toward the blue energy dream by triboelectric nanogenerator networks.", Nano Energy, 39: 9-23, 2017 - DOI: 10.1016/j.nanoen.2017.06.035

[28] J. Luo, L. Xu, W. Tang, T. Jiang, F. Ru, F. Yao, K. Pang, L. Chen, Y. Zhang and Z. L. Wang, "Direct-Current Triboelectric Nanogenerator Realized by Air Breakdown Induced Ionized Air Channel.", Advanced Energy Materials, 8(27): 1800889, 2018 - DOI: 10.1002/aenm.201800889

[29] Hinchet, Ronan, et al. "Understanding and modeling of triboelectric-electret nanogenerator." Nano energy 47 (2018): 401-409. DOI: 10.1016/j.nanoen.2018.02.030.

[30] H. Zhang, Y. Lu, A. Ghaffarinejad and P. Basset, "Progressive Contact-separate Triboelectric Nanogenerator Based on Conductive Polyurethane Foam Regulated with a Bennet Doubler Conditioning Circuit.", Nano Energy, vol. 51, pp. 10-18, 2018 - DOI: 10.1016/j.nanoen.2018.06.038

[31] S. Wang, Y. Xie, S. Niu, L. Lin and Z. L. Wang, "Freestanding Triboelectric-Layer-Based Nanogenerators for Harvesting Energy from a Moving Object or Human Motion in Contact and Non-contact Modes.", Advanced Materials, 26(18): 2818-2824, 2014 - DOI: 10.1002/adma.201305303

[32] Niu, Simiao, et al. "Theory of freestanding triboelectric-layer-based nanogenerators." Nano Energy 12 (2015): 760-774. DOI: 10.1016/j.nanoen.2015.01.013.

[33] Kester, Walt, Brian Erisman, and Gurjit Thandi. "Switched capacitor voltage converters." Power and Thermal Management Design Techniques Seminars, Section IV, Analog Device Design Handbook. 1998. ISBN-0-916550-19-2.

[34] Peschot, Alexis, et al. "Contact bounce phenomena in a MEM switch." Electrical Contacts (Holm), 2012 IEEE 58th Holm Conference on. IEEE, 2012. DOI: 10.1109/holm.2012.6336560.

[35] Hinchet, Ronan, et al. "Understanding and modeling of triboelectric-electret nanogenerator." Nano energy 47 (2018): 401-409. DOI: 10.1016/j.nanoen.2018.02.030.

[36] Basset, Philippe, et al. "A batch-fabricated and electret-free silicon electrostatic vibration energy harvester." Journal of Micromechanics and Microengineering 19.11 (2009): 115025. DOI: 10.1088/0960-1317/19/11/115025. 
[37] Truong, Binh Duc, Cuong Phu Le, and Einar Halvorsen. "Analysis of electrostatic energy harvesters electrically configured as Bennet's doublers." IEEE Sensors Journal 17.16 (2017): 5180-5191. DOI: 10.1109/JSEN.2017.2723571.

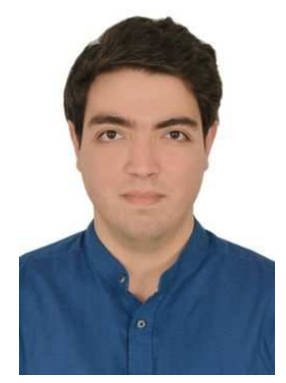

Mohamed Aymen Ben Ouanes was born in Tunis, Tunisia, in 1990. He received his Engineer's degree in Mechatronics from the National Engineering School of Sousse (ENISo) Tunisia in 2015. His current research topics include mechanical energy harvesting.

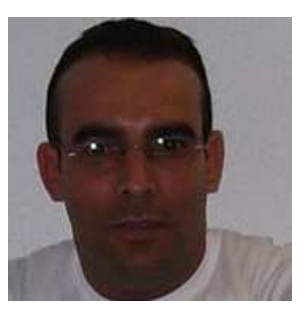

Hatem Samaali obtained his Ph.D. degree in Microelectronics from National Engineering School of Sfax (ENIS), Tunisia in 2011. He was a post-doc at ESIEE Paris, France, from 2016 to 2018 where he worked on NEMS-based adiabatic circuits. His current research topics include nonlinear dynamics in NEMS/MEMS Switch devices and Energy Harvesting.

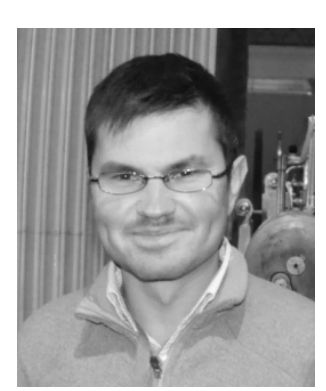

GalaykoDimitri Galayko graduated from Odessa State Polytechnich University, Ukraine, in 1998, he received the master's degree from the Institut of Applied Sciences of Lyon (INSA-LYON, France) in 1999 and the Ph.D. degree from the University Lille-I in 2002. He made his Ph.D. thesis with the Institute of Microelectronics and Nanotechnologies (IEMN, Lille, France). The topic of his Ph.D. dissertation was the design of microelectromechanical silicon filters and resonators for radiocommunications. Since 2005 , he has been an associate professor with the LIP6 Laboratory, Sorbonne Université-University Paris-VI (Pierre et Marie Curie). His research interests include study, modeling, and design of nonlinear integrated circuits for sensor interface and for mixed-signal applications.

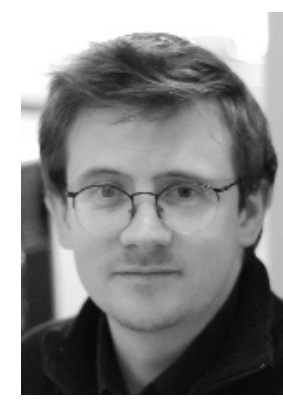

Philippe Basset is professor at Université Paris-Est / ESIEE Paris. He received his Ph.D from IEMN / University of Lille in 2003 in the areas of microelectronic and micro-electro-mechanical-systems (MEMS). In 2004 he was a post-doc at CMU, Pittsburgh, USA and he joined ESIEE Paris in 2005. His current research interests include micro-power sources for autonomous MEMS and micro/nano-structuration of silicon. He currently serves in the International Steering Committee of the PowerMEMS conference since 2015 and he is deputy director of the ESYCOM laboratory. 


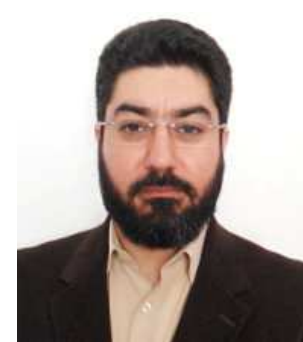

Fehmi Najar, is professor of mechanical engineering at the Tunisia Polytechnic School, University of Carthage, Tunisia. He received an Engineering Diploma in Mechanical Engineering from the National Engineering School of Tunis in 1997, and an M.S. in Structural Dynamics from the Ecole Centrale de Paris, France, in 1998. After graduation, he worked as Technical Manager in the Graphic Art industry for a period of 6 years. He obtained his PhD in Mechanical Engineering from the National Engineering School of Tunis in 2008. His research interests include MEMS and NEMS, structural nonlinear dynamics, smart materials, energy harvesting and multi-body dynamics. 


\section{Graphical Abstract}

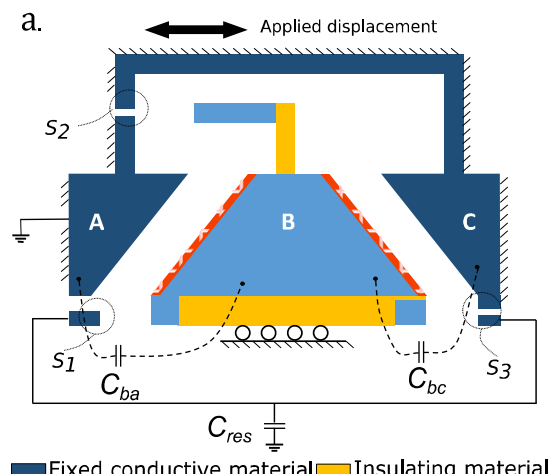

$\square$ Fixed conductive material $\square$ Insulating material $\square$ Moving conductive materialnTriboelectric Patch

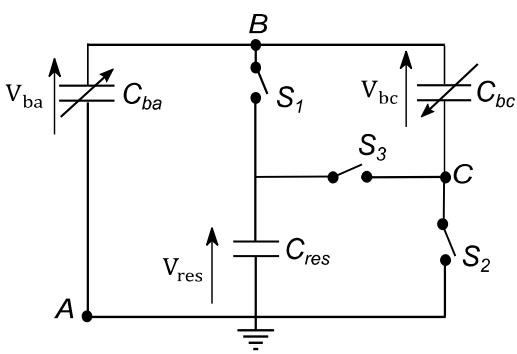

b.
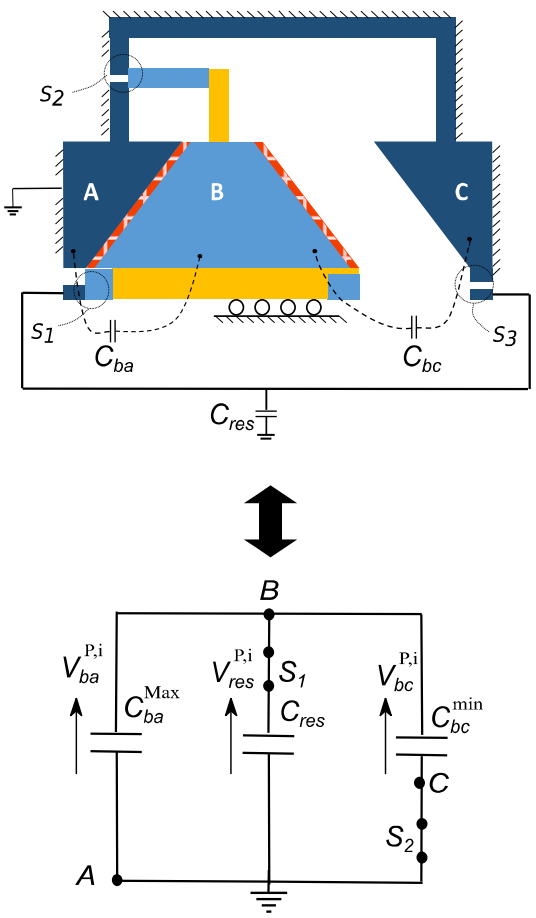

c.
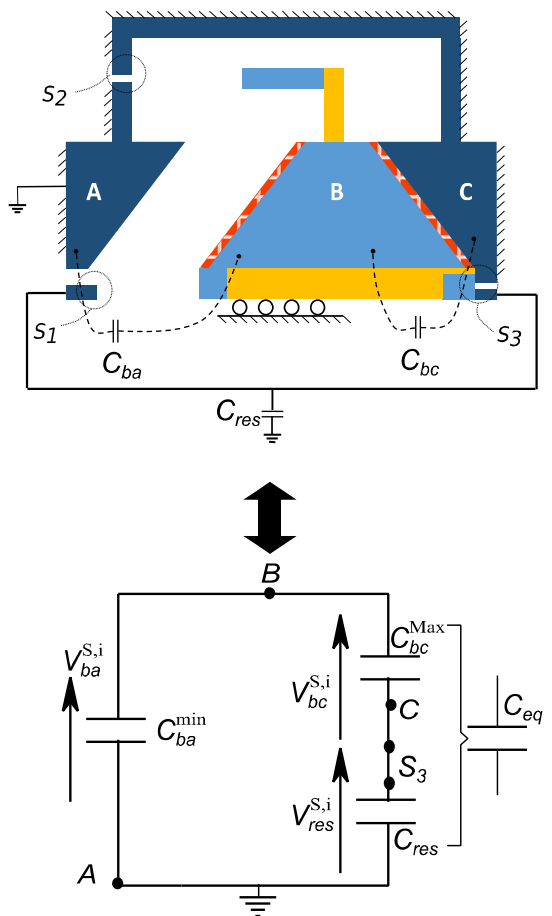

We report a new type of triboelectric nanogenerator (TENG) having alternating and self-actuated series-to-parallel interfaces based on self-synchronized mechanical switches. It has been inspired from the Bennet doubler electrical machine. The TENG is composed of a freestanding electrode, two anti-phase variable capacitors excited by the external vibrations, and a reservoir capacitor. The absence of diodes and their unavoidable voltage threshold for signal rectification, combined with the boost introduced by the Bennet-like doubler structure, can largely improve the energy conversion efficiency of TENGs, especially during the start-up. 